\title{
The genus Spiroplasma and its non-helical descendants: phylogenetic classification, correlation with phenotype and roots of the Mycoplasma mycoides clade
}

\author{
Gail E. Gasparich, ${ }^{1}$ Robert F. Whitcomb, ${ }^{2}$ Deborah Dodge, ${ }^{3}$ \\ Frank E. French, ${ }^{4}$ John Glass ${ }^{5}$ and David L. Williamson ${ }^{6}$ \\ ${ }^{1}$ Department of Biological Sciences, Towson University, Towson, MD 21252, USA \\ ${ }^{2}$ US Department of Agriculture, Vegetable Laboratory, BARC, Beltsville, MD 20705, USA \\ ${ }^{3}$ Business Group Diagnostics, Bayer Corporation, Emeryville, CA 94608, USA \\ ${ }^{4}$ Department of Biology, Georgia Southern University, Statesboro, GA 30460, USA \\ ${ }^{5}$ Institute for Biological Energy Alternatives, 1901 Research Boulevard, Suite 600, Manassas, \\ VA 20850, USA \\ ${ }^{6}$ Department of Anatomical Sciences, State University of New York, Stony Brook, NY 11794, USA
}

Correspondence

Gail E. Gasparich

ggasparich@towson.edu

The genus Spiroplasma (helical mollicutes: Bacteria: Firmicutes: Mollicutes: Entomoplasmatales: Spiroplasmataceae) is associated primarily with insects. The Mycoplasma mycoides cluster (sensu Weisburg et al. 1989 and Johansson and Pettersson 2002) is a group of mollicutes that includes the type species - Mycoplasma mycoides - of Mycoplasmatales, Mycoplasmataceae and Mycoplasma. This cluster, associated solely with ruminants, contains five other species and subspecies. Earlier phylogenetic reconstructions based on partial 16S rDNA sequences and a limited sample of Spiroplasma and Mycoplasma sequences suggested that the genus Mycoplasma was polyphyletic, as the M. mycoides cluster and the grouping that consisted of the hominis and pneumoniae groups of Mycoplasma species were widely separated phylogenetically and the M. mycoides cluster was allied with Spiroplasma. It is shown here that the M. mycoides cluster arose from Spiroplasma through an intermediate group of non-helical spiroplasmal descendants - the Entomoplasmataceae. As this conclusion has profound implications in the taxonomy of Mollicutes, a detailed phylogenetic study of Spiroplasma and its non-helical descendants was undertaken. These analyses, done with maximum-parsimony, provide cladistic status; a new nomenclature is introduced here, based on 'bottom-up' rather than 'top-down' clade classification. The order Entomoplasmatales consists of four major clades: (i) the Mycoides-Entomoplasmataceae clade, which contains M. mycoides and its allies and Entomoplasma and Mesoplasma species and is a sister lineage to (ii) the Apis clade of Spiroplasma. Spiroplasma and the Entomoplasmataceae are paraphyletic, but this status does not diminish their phylogenetic usefulness. Five species that were previously unclassified phylogenetically are basal to the Apis clade sensu strictu and to

Published online ahead of print on 23 January 2004 as DOI 10.1099/ijs.0.02688-0.

Abbreviations: DF, deformation; MI, metabolism inhibition; PES, polyoxyethelene sorbitan; PHUH clade, Pneumoniae-Hominis-UreaplasmaHaemoplasma clade; SEM clade, Spiroplasma-Entomoplasmataceae-Mycoides clade.

The GenBank/EMBL/DDBJ accession numbers for new Spiroplasma 16S rDNA sequences are: Spiroplasma sp. strain 277F, AY189312; Spiroplasma sp. strain LB-12, AY189313; S. insolitum, AY189133; S. floricola, AY189131; S. syrphidicola, AY189309; S. chrysopicola, AY189127; Spiroplasma sp. strain TAAS-1, AY189314; S. culicicola, AY189129; S. velocicrescens, AY189311; S. sabaudiense, AY189308; S. corruscae, AY189128; Spiroplasma sp. strain CB-1, AY189315; Spiroplasma sp. strain Ar 1357, AY189316; S. turonicum, AY189310; S. litorale, AY189306; S. lampyridicola, AY189134; S. leptinotarsae, AY189305; Spiroplasma sp. strain W115, AY189317; S. chinense, AY189126; S. diminutum, AY189130; S. alleghenense, AY189125; Spiroplasma sp. strain TIUS-1, AY189318; Spiroplasma sp. strain BIUS-1, AY189319; S. montanense, AY189307; S. helicoides, AY189132; Spiroplasma sp. BARC 1901, AY189320.

Tables summarizing the phylogenetic trees constructed for the genus Spiroplasma and their support are available as supplementary material in IJSEM Online. 
the Mycoides clade. One of these species, Spiroplasma sp. TIUS-1, has very poor helicity and a very small genome ( $840 \mathrm{kbp}$ ); this putative species can be envisioned as a 'missing link' in the evolution of the Mycoides-Entomoplasmataceae clade. The other two Spiroplasma clades are: (iii) the Citri-Chrysopicola-Mirum clade (serogroups I, II, V and VIII) and (iv) the ixodetis clade (serogroup $\mathrm{VI}$ ). As Mesoplasma lactucae represents a basal divergence within the Mycoides-Entomoplasmataceae clade, and as Entomoplasma freundtii is basal to the Mycoides clade, M. mycoides and its allies must have arisen from an ancestor in the Entomoplasmataceae. The paraphyletic grouping that consists of the Hominis and Pneumoniae groups (sensu Johansson \& Pettersson 2002) of Mycoplasma species contains the ancestral roots of Ureaplasma spp. and haemoplasmas. This clade is a sister lineage to the Entomoplasmatales clade. Serological classifications of spiroplasma are very highly supported by the trees presented. Genome size and $\mathrm{G}+\mathrm{C}$ content of micro-organismal DNA were moderately conserved, but there have been frequent and polyphyletically distributed genome reductions. Sterol requirements were polyphyletic, as was the ability to grow in the presence of polyoxyethylene sorbitan-supplemented, but not serum-supplemented, media. As this character is not phylogenetically distributed, Mesoplasma and Entomoplasma should be combined into a single genus. The phylogenetic trees presented here confirm previous reports of polyphyly of the genus Mycoplasma. As both clades of Mycoplasma contain several species of great practical importance, a change of the genus name for species in either clade would have immense practical implications. In addition, a change of the genus name for $M$. mycoides would have to be approved by the Judicial Commission. For these reasons, the Linnaean and phylogenetic classifications of Mycoplasma must for now be discrepant.

\section{INTRODUCTION}

The genus Spiroplasma contains a group of motile, helical, wall-less prokaryotes that are associated primarily with insects, but much less frequently with ticks and plants (Williamson et al., 1989, 1998; Tully \& Whitcomb, 1990). In addition to their unique cellular morphology, species of this genus have attracted recent attention as the root of a small clade that contains the type species of the genus Mycoplasma. The genus Spiroplasma was discovered relatively recently. The first species described in this genus, Spiroplasma citri (Saglio et al., 1973), is the aetiological agent of citrus stubborn disease (Calavan \& Bové, 1989) and resides in an obligate cycle in the plant phloem and the insect vector. Another spiroplasma - thought at the time to be a spirochaete - was shown to cause a sex-ratio abnormality in Drosophila (Poulson \& Sakaguchi, 1961; Williamson \& Poulson, 1979). A third spiroplasma, eventually named Spiroplasma kunkelii, discovered shortly before S. citri was described (Davis et al., 1972; Whitcomb et al., 1986), is also an inhabitant of the plant phloem/insect habitat (Hackett \& Clark, 1989). Spiroplasmas were then found to inhabit ticks (Burgdorfer et al., 1975; Tully et al., 1976, 1982, 1995). One of these, Spiroplasma mirum, can cause experimental disease in suckling rodents (Tully et al., 1977). It was not realized until 1977 (Clark, 1977, 1982) that the major reservoir of spiroplasmas was insects and that the surfaces, rather than the phloem, of flowers and other plant parts were the major site for spiroplasma acquisition and transmission (Davis, 1978; McCoy et al., 1979; Clark et al., 1987).

The general phylogenetic position of the genus Spiroplasma was determined as a result of the pioneering work of Carl
Woese and his associates [summarized by Woese (1987)], which utilized 16S rRNA for the study of prokaryote phylogeny. As the class Mollicutes was of special interest (Woese et al., 1985), these studies led to an in-depth study of its evolution [reviewed by Johansson \& Pettersson (2002)]. The class Mollicutes was shown to be a terminus in the evolution of Gram-positive bacteria. Early studies (Woese et al., 1980) indicated that the class Mollicutes was divided into four major phylogenetic groups - a clade that contained Anaeroplasmatales and Acholeplasmatales, a clade that consisted of the hominis and pneumoniae groups of Mycoplasma, a clade that contained Spiroplasma and Mycoplasma mycoides and a monospecific clade that contained Asteroleplasma anaerobium. Although early studies were non-committal on the monophyly of the AcholeplasmatalesAnaeroplasma and Spiroplasma-EntomoplasmataceaeMycoides clades (Woese et al., 1980), subsequent phylogenetic analyses have led workers to hypothesize that they are monophyletic. However, the studies of Weisburg et al. (1989) indicated that one of the three major groups of Mollicutes - the asteroleplasma group - may be allied more closely with certain genera of low- $G+C$ content, Grampositive bacteria than with other mollicutes. Thus, walllessness probably evolved at least twice in the evolution of Gram-positive bacteria. In addition to the asteroleplasma group, Weisburg and colleagues defined the pneumoniae, hominis, anaeroplasma and spiroplasma groups.

The M. mycoides cluster of Weisburg et al. (1989) is a group that, with all recent additions, contains 23 species (J. G. Tully, personal communication). Five of these form a monophyletic grouping that is restricted to ruminant 
animals. One of these, $M$. mycoides, is the type species of Mollicutes, Mycoplasmataceae and Mycoplasma. M. mycoides is divided into several subtaxa (some of which have been recognized at the subspecies level) that differ in their host range, pathogenicity and serological and genomic characters (Heldtander et al., 1998; Persson, 2002). M. mycoides subsp. mycoides SC is the causative agent of contagious bovine pleuropneumonia [reviewed by Persson (2002)]. This disease, which was recognized as long ago as the middle ages (reviewed by Provost et al., 1987), is the only bacterial disease on the A-list of communicable animal diseases (FAO EMPRES, 2000). This classification places it as one of the 15 most serious animal diseases in the world. The agent was cultivated in 1898 by Nocard and Roux. DujardinBeaumetz, a co-worker of Nocard and Roux, introduced filters to separate the organism from contaminants and was the first to cultivate the organisms on agar, where they formed fried-egg colonies [summarized by Bové et al. (1994)]. The organism was described as Asterococcus mycoides in 1910 and later reclassified in a novel genus, Mycoplasma (Nowak, 1929). In 1956, the current classification was established (Edward \& Freundt, 1956). A second subspecies of the M. mycoides cluster, Mycoplasma capricolum subsp. capripneumoniae, is a serious pathogen of caprine animals (Johansson \& Pettersson, 2002). A genomesequencing project for $M$. mycoides has shown that the genome is $1140 \mathrm{kbp}$ in size, with a very low $\mathrm{G}+\mathrm{C}$ content of $24 \mathrm{~mol} \%$. The M. mycoides genome has 1067 fully annotated ORFs and many have been correlated with metabolic functions (Persson, 2002).

Earlier phylogenetic studies (Woese et al., 1980; Weisburg et al., 1989; Maniloff, 1992) produced a major surprise - that some members of the genus Mycoplasma, including the type species, M. mycoides, appeared to belong to the spiroplasma group and that the genus Mycoplasma, like Mollicutes, might therefore be polyphyletic. These studies suggested that a small group of species, including M. mycoides and its cohorts - all from bovine and caprine sources - were placed properly in the spiroplasma group of mollicutes.

The discovery of non-helical mollicutes in the insect gut/ plant surface habitat (Clark, 1977; Davis, 1978; Clark et al., 1986; Tully et al., 1994) revealed a large assemblage of previously unrecognized mollicutes. These organisms appeared at first to be Acholeplasma or Mycoplasma species, but some were later found to be phylogenetically distinct from those genera (Weisburg et al., 1989). This newly discovered group of organisms was later referred to a novel family, Entomoplasmataceae (Tully et al., 1993), which had two genera. Entomoplasma was proposed for organisms that did not require sterol and Mesoplasma was proposed for certain species that could grow in the absence of sterol if, and only if, cultures of the organism were grown in media that were supplemented with $0 \cdot 04 \%$ polyoxyethelene sorbitan (PES).

The apparent polyphyly of Mycoplasma has profound implications for mollicute taxonomy. M. mycoides is the type species of the order Mycoplasmatales, the family
Mycoplasmataceae and the genus Mycoplasma. If this species was shown conclusively to be phylogenetically remote from other Mycoplasma species, in an era that features strong attempts to reconcile binomial and phylogenetic classification, a major taxonomic quandary would be presented. Earlier phylogenies (Weisburg et al., 1989; Maniloff, 1992) were derived from a database of largely incomplete sequences and were analysed by phenetic analytical methods (distance and the largely phenetic neighbour-joining method). However, now that a much more complete dataset exists and cladistics is becoming one of the cornerstones of microbial systematics (Ludwig \& Schleifer, 1999), it is important that this profound conclusion be revisited and confirmed.

An appendix of the taxonomic terms used in the text is given in Table 1.

\section{METHODS}

Strains and growth conditions. The strains used in this study are listed in Table 2. Most strains of Spiroplasma, Entomoplasma and Mesoplasma were isolated, cloned and preserved in laboratories at USDA, Beltsville, MD, USA; SUNY, Stony Brook, NY, USA; or at the NIAID laboratory at Frederick, MD, USA. Type or representative strains were submitted to, and are available from, the American Type Culture Collection (ATCC). Representative cultures of these strains and of other non-type strains have been deposited at Purdue University (West Layfayette, IN,USA). Most Spiroplasma, Mesoplasma and Entomoplasma strains were grown in M1D broth medium (Whitcomb, 1983), but some were cultured in SP-4 broth medium (Whitcomb, 1983). Cultures of Spiroplasma leptinotarsae were grown in DCCM broth medium (Hackett et al., 1996a). All cultures were maintained at their optimum temperatures (Konai et al., 1996).

DNA isolation. DNA was extracted by using either the chelex resin/ boil protocol (Walsh et al., 1991) or the SDS lysis protocol, as described previously (Gasparich et al., 1993).

In vitro amplification and DNA sequencing of the 16S rRNA gene. 16S rRNA genes of the species investigated were PCR-amplified from genomic DNA. PCR sequence mixtures contained $2 \mu$ extracted DNA, $50 \mu \mathrm{l}$ MicroSeq 16S rDNA PCR kit (PE/Applied Biosystems) PCR mastermix and $48 \mu \mathrm{l}$ water. PCR conditions were those recommended by the manufacturer (PE/Applied Biosystems). The PCR product generated was $1540 \mathrm{bp}$ in length. PCR products were purified by using a Microcon-100 column (Amicon), following the protocol designated by the manufacturer. Reaction products were cyclesequenced by using a MicroSeq $16 \mathrm{~S}$ rRNA Gene Sequencing kit (PE/ Applied Biosystems). Excess dye terminators were removed by using Centri-Sep spin columns (Princeton Separations) as recommended by the manufacturer. Reaction products were then dried in a Speed Vac (Savant) and resuspended in $4 \mu \mathrm{l}$ sequencing gel loading buffer (25 mM EDTA, $50 \mathrm{mg}$ Blue Dextran $\mathrm{ml}^{-1}$ and 1:5 deionized formamide). A $2 \mu \mathrm{l}$ aliquot was then loaded onto an ABI 377 DNA sequencer (PE/Applied Biosystems) and electrophoresed at $1650 \mathrm{~V}$ and $52^{\circ} \mathrm{C}$ for $7 \mathrm{~h}$.

Assembly of sequences. Sequences were analysed by using the software programs Sequencing Analysis (PE/Applied Biosystems) and Factura (PE/Applied Biosystems). Analysed sequences were then assembled and edited by using Auto Assembler (PE/Applied Biosystems) and a consensus sequence was generated.

Nucleotide sequence accession numbers. The new $16 \mathrm{~S}$ rDNA sequences that were used in this study have been deposited in GenBank under the accession numbers listed in Table 2. 
Table 1. Taxonomic terms used in the text

More detailed definitions of cladistic terms are provided at http://www.bioinf.org/molsys/glossary.html.

\begin{tabular}{|c|c|}
\hline Term & Definition \\
\hline Autapomorphy & $\begin{array}{l}\text { An apomorphy that diagnoses a terminus, but that is uninformative about relationships to other terminals and is } \\
\text { therefore of no use for cladistic tree-building }\end{array}$ \\
\hline $\begin{array}{l}\text { Apomorphy (adj. } \\
\text { apomorphic) }\end{array}$ & A relatively derived, advanced or unique character state \\
\hline Attribute & Possession of a particular feature by an organism \\
\hline Character & A heritable attribute that varies among termini and that is therefore useful for phylogenetic reconstruction \\
\hline Clade & A monophyletic group (a branch on a cladogram) \\
\hline Cladogram & A tree that comprises nested clades \\
\hline Consensus & $\begin{array}{l}\text { A class of methods that is used to estimate the amount of agreement among incongruent or partially congruent } \\
\text { trees. A majority-rule consensus tree identifies all clades that are found in }>50 \% \text { of input trees }\end{array}$ \\
\hline $\begin{array}{l}\text { Long-branch } \\
\text { attraction }\end{array}$ & $\begin{array}{l}\text { A process in cladistic analysis that results in tree positions that are artificially close; may occur when a tree } \\
\text { branch represents a large evolutionary distance }\end{array}$ \\
\hline Monophyly & $\begin{array}{l}\text { A group that has a unique origin in a single ancestral species; it includes the ancestor and all of its descendants. } \\
\text { It is recognized by a homologous character state (synapomorphy) in all of its members }\end{array}$ \\
\hline Outgroup & $\begin{array}{l}\text { A terminal taxon (or group of taxa), preferably the sister group of the ingroup, that is used to root a cladogram } \\
\text { (cf. ingroup). The root is placed between the outgroup(s) and the ingroup. Multiple outgroups may be used }\end{array}$ \\
\hline $\begin{array}{l}\text { Paraphyly (adj. } \\
\text { paraphyletic) }\end{array}$ & $\begin{array}{l}\text { A paraphyletic group originates from a single common ancestor (which is included in the group), but does not } \\
\text { include all of the descendants of that ancestor. Its members share only ancestral character states; they do not } \\
\text { uniquely share any synapomorphies. In micro-organisms, paraphyly may be confounded with polyphyly, as a } \\
\text { result of presumed high extinction rates }\end{array}$ \\
\hline Phenetic & $\begin{array}{l}\text { Similarity of characters without regard to the distinction between synapomorphy, homoplasy and symplesiomorphy. } \\
\text { Phenetic methods are poor at reconstructing phylogeny }\end{array}$ \\
\hline Phylogenetic signal & $\begin{array}{l}\text { A property of data that indicates the presence of informative characters, whose presence affects the topology of } \\
\text { cladistic trees (cf. uninformative characters) }\end{array}$ \\
\hline $\begin{array}{l}\text { Plesiomorphy (adj. } \\
\text { plesiomorphic) }\end{array}$ & A relatively primitive or ancestral character state \\
\hline Polarity & $\begin{array}{l}\text { Evolutionary ordering of character states, determined either independently of tree construction (direct method) or, } \\
\text { more usually, from a rooted phylogenetic tree (indirect method) }\end{array}$ \\
\hline $\begin{array}{l}\text { Polyphyly (adj. } \\
\text { polyphyletic) }\end{array}$ & $\begin{array}{l}\text { A group that does not include a unique common ancestor, i.e. it has multiple evolutionary origins. Designation } \\
\text { based upon convergent characters }\end{array}$ \\
\hline Polytomy & $\begin{array}{l}\text { A branch-point in a tree with more than two descendent branches. A polytomy referred to as 'hard' results from } \\
\text { an absence of data to resolve branching dichotomously. Frequently found in groups whose members are too } \\
\text { closely related to be resolved with the method used for analysis }\end{array}$ \\
\hline sensu latu & $\begin{array}{l}\text { An appendix to a taxic name used to define a taxon whose composition has been redefined, but whose name has } \\
\text { been retained. See sensu strictu }\end{array}$ \\
\hline sensu strictu & $\begin{array}{l}\text { Used to define a taxon as originally circumscribed, prior to a recent change in the definition of the group's } \\
\text { boundaries or composition }\end{array}$ \\
\hline Synapomorphy & An apomorphy that is shared by two or more termini and therefore diagnoses a clade or monophyletic group \\
\hline Terminus & $\begin{array}{l}\text { One of the units whose collective phylogeny is reconstructed; in other words, the undivided tips of a tree (usually } \\
\text { contemporary taxa). Termini may be higher taxa, species, populations, individuals, fossils or even genes }\end{array}$ \\
\hline Topology & Structural details of trees \\
\hline Total evidence & Reconstruction of phylogeny by analysing combined data of different kinds \\
\hline $\begin{array}{l}\text { Uninformative } \\
\text { character }\end{array}$ & $\begin{array}{l}\text { A character that provides no phylogenetic signal. In maximum-parsimony methods, only characters whose number } \\
\text { of steps can vary on trees are informative; autapomorphic and invariant characters are uninformative }\end{array}$ \\
\hline
\end{tabular}

Phylogenetic analyses. Sequences were aligned by using CLUSTALX (Thompson et al., 1994) and then aligned manually in MacClade (Maddison \& Maddison, 1992). Maximum-parsimony, maximumlikelihood, distance and neighbour-joining analyses were performed by using PAUP (version 4.0b10; Swofford, 1998). Parameters for analyses are presented in Supplementary Table A (available in IJSEM Online).

\section{RESULTS AND DISCUSSION}

\section{Choice of phylogenetic method}

As indicated, trees generated by using four different phylogenetic methods were used in the analysis of the $16 \mathrm{~S}$ 
Table 2. Bacterial strains included in this study, their group designations and GenBank accession numbers for their $16 \mathrm{~S}$ rRNA gene sequences

\begin{tabular}{|c|c|c|}
\hline Genus, species and strain & $\begin{array}{c}\text { Group } \\
\text { designation }\end{array}$ & $\begin{array}{c}\text { GenBank } \\
\text { accession no. }\end{array}$ \\
\hline Spiroplasma citri Maroc $\mathrm{R} 8 \mathrm{~A} 2^{\mathrm{T}}$ & $\mathrm{I}-1$ & M23942 \\
\hline Spiroplasma melliferum $\mathrm{BC}-3^{\mathrm{T}}$ & $\mathrm{I}-2$ & AY325304 \\
\hline Spiroplasma sp. $277 \mathrm{~F}$ & $\mathrm{I}-4$ & AY189312 \\
\hline Spiroplasma sp. LB-12 & $\mathrm{I}-5$ & AY189313 \\
\hline Spiroplasma insolitum M55 ${ }^{\mathrm{T}}$ & I-6 & AY189133 \\
\hline Spiroplasma floricola $23-6^{\mathrm{T}}$ & III & AY189131 \\
\hline Spiroplasma apis $\mathrm{B} 31^{\mathrm{T}}$ & IV & M23937 \\
\hline Spiroplasma mirum $\mathrm{SMCA}^{\mathrm{T}}$ & V & M24662 \\
\hline Spiroplasma ixodetis $\mathrm{Y}^{3} 2^{\mathrm{T}}$ & VI & M24477 \\
\hline Spiroplasma monobiae MQ-1 $1^{\mathrm{T}}$ & VII & M24481 \\
\hline Spiroplasma syrphidicola $\mathrm{EA}-1^{\mathrm{T}}$ & VIII-1 & AY189309 \\
\hline Spiroplasma chrysopicola $\mathrm{DF}-1^{\mathrm{T}}$ & VIII-2 & AY189127 \\
\hline Spiroplasma sp. TAAS-1 & VIII-3 & AY189314 \\
\hline Spiroplasma clarkii $\mathrm{CN}-5^{\mathrm{T}}$ & IX & M24474 \\
\hline Spiroplasma culicicola AES- $1^{\mathrm{T}}$ & $\mathrm{X}$ & AY189129 \\
\hline Spiroplasma velocicrescens $\mathrm{MQ}-4^{\mathrm{T}}$ & XI & AY189311 \\
\hline Spiroplasma diabroticae $\mathrm{DU}-1^{\mathrm{T}}$ & XII & M24482 \\
\hline Spiroplasma sabaudiense Ar- $1343^{\mathrm{T}}$ & XIII & AY189308 \\
\hline Spiroplasma corruscae EC-1 $1^{\mathrm{T}}$ & XIV & AY189128 \\
\hline Spiroplasma sp. CB-1 & $\mathrm{XVI}-2$ & AY189315 \\
\hline Spiroplasma sp. Ar 1357 & XVI-3 & AY189316 \\
\hline Spiroplasma turonicum Tab- $4 \mathrm{c}^{\mathrm{T}}$ & XVII & AY189310 \\
\hline Spiroplasma litorale $\mathrm{TN}-1^{\mathrm{T}}$ & XVIII & AY189306 \\
\hline Spiroplasma lampyridicola $\mathrm{PUP}-1^{\mathrm{T}}$ & XIX & AY189134 \\
\hline Spiroplasma leptinotarsae LD-1B & $\mathrm{XX}$ & AY189305 \\
\hline Spiroplasma sp. W115 & XXI & AY189317 \\
\hline Spiroplasma taiwanense CT- $1^{\mathrm{T}}$ & XXII & M24476 \\
\hline Spiroplasma gladiatoris $\mathrm{TG}-1^{\mathrm{T}}$ & XXIII & M24475 \\
\hline Spiroplasma chinense $\mathrm{CCH}^{\mathrm{T}}$ & XXIV & AY189126 \\
\hline Spiroplasma diminutum CUAS- $1^{\mathrm{T}}$ & XXV & AY189130 \\
\hline Spiroplasma alleghenense PLHS $-1^{\mathrm{T}}$ & XXVI & AY189125 \\
\hline Spiroplasma sp. TIUS-1 & XXIX & AY189318 \\
\hline Spiroplasma sp. BIUS-1 & $\mathrm{XXX}$ & AY189319 \\
\hline Spiroplasma montanense HYOS $-1^{\mathrm{T}}$ & XXXI & AY189307 \\
\hline Spiroplasma helicoides TABS- $2^{\mathrm{T}}$ & XXXII & AY189132 \\
\hline Spiroplasma sp. BARC 1901 & XXXIV & AY189320 \\
\hline Mesoplasma entomophilum $\mathrm{TAC}^{\mathrm{T}}$ & $\mathrm{NA}$ & M23931 \\
\hline Mesoplasma lactucae $831-\mathrm{C} 4^{\mathrm{T}}$ & NA & AF303132 \\
\hline Entomoplasma ellychniae ELCN-1 ${ }^{\mathrm{T}}$ & NA & M24292 \\
\hline Entomoplasma freundtii BARC $318^{\mathrm{T}}$ & NA & AF036954 \\
\hline Entomoplasma melaleucae $\mathrm{M1}^{\mathrm{T}}$ & NA & M24478 \\
\hline Mycoplasma mycoides subsp. mycoides $\mathrm{PG} 1^{\mathrm{T}}$ & NA & U26039 \\
\hline Mycoplasma capricolum subsp. capripneumoniae Yatta B & NA & AF202928 \\
\hline Mycoplasma putrefaciens $\mathrm{KS}^{\mathrm{T}}$ & NA & M23938 \\
\hline Mycoplasma cottewii $\mathrm{VIS}^{\mathrm{T}}$ & NA & U67945 \\
\hline Mycoplasma yeatsii $\mathrm{GIH}^{\mathrm{T}}$ & NA & U67946 \\
\hline Mycoplasma pneumoniae $\mathrm{FH}^{\mathrm{T}}$ & NA & M29061 \\
\hline Mycoplasma hominis $\mathrm{PG} 21^{\mathrm{T}}$ & NA & M24473 \\
\hline Mycoplasma synoviae WVU $1853^{\mathrm{T}}$ & NA & X52083 \\
\hline Mycoplasma pulmonis $\mathrm{PG} 34^{\mathrm{T}}$ & NA & M23941 \\
\hline Mycoplasma neurolyticum Type $\mathrm{A}^{\mathrm{T}}$ & NA & M23944 \\
\hline Mycoplasma sualvi Mayfield $\mathrm{B}^{\mathrm{T}}$ & NA & M23936 \\
\hline
\end{tabular}


Table 2. cont.

\begin{tabular}{|lcl|}
\hline Genus, species and strain & $\begin{array}{c}\text { Group } \\
\text { designation }\end{array}$ & $\begin{array}{c}\text { GenBank } \\
\text { accession no. }\end{array}$ \\
\hline Mycoplasma equigenitalium $\mathrm{T}^{\mathrm{T}} 7^{\mathrm{T}}$ & $\mathrm{NA}$ & $\mathrm{AF} 221120$ \\
Mycoplasma bovis $422 / 88$ & $\mathrm{NA}$ & $\mathrm{AF} 332757$ \\
Mycoplasma lipophilum MaBy & $\mathrm{T}$ & $\mathrm{NA} 24581$ \\
Mycoplasma cavipharyngis $117 \mathrm{C}^{\mathrm{T}}$ & $\mathrm{NA}$ & $\mathrm{AF} 125879$ \\
Ureaplasma urealyticum $960^{\mathrm{T}}$ & $\mathrm{NA}$ & $\mathrm{M} 23935$ \\
Acholeplasma laidlawii JA1 & $\mathrm{NA}$ & $\mathrm{M} 23932$ \\
Phytoplasma sp. Vigna LL & $\mathrm{NA}$ & $\mathrm{AJ} 289195$ \\
Mycoplasma haemomuris Shizuoka & $\mathrm{NA}$ & $\mathrm{U} 82963$ \\
Anaeroplasma bactoclasticum $\mathrm{JR}^{\mathrm{T}}$ & $\mathrm{NA}$ & $\mathrm{M} 25049$ \\
Asteroleplasma anaerobium $161^{\mathrm{T}}$ & $\mathrm{NA}$ & $\mathrm{M} 22351$ \\
Erysipelothrix rhusiopathiae $\alpha-\mathrm{P} 15$ & $\mathrm{NA}$ & $\mathrm{M} 23728$ \\
Clostridium innocuum $\mathrm{B}-3$ & $\mathrm{NA}$ & $\mathrm{M} 23732$ \\
Bacillus subtilis TB11 & $\mathrm{NA}$ & $\mathrm{AF} 058766$ \\
Escherichia coli (strain not specified) & $\mathrm{NA}$ & $\mathrm{J} 01859$ \\
\hline
\end{tabular}

rDNA sequence dataset (maximum-parsimony, distance, neighbour-joining and maximum-likelihood). All four methods have been used previously to analyse mollicute phylogeny (e.g. Woese et al., 1980; Rogers et al., 1985; Weisburg et al., 1989; Maniloff, 1992; Johansson \& Pettersson, 2002). The extensive work published by K. E. Johansson's group [reviewed in part by Johansson \& Pettersson (2002)] has been done by using neighbourjoining, maximum-parsimony and maximum-likelihood. The large and globally inclusive trees generated by Gundersen et al. (1994) were constructed by using maximum-parsimony. Distance analyses (using $p$-distance) were performed in the initial work on mollicute phylogeny by Woese et al. (1980) and Weisburg et al. (1989), and neighbour-joining analyses were performed by Maniloff (1992). We are aware that each method has its detractors, especially distance (e.g. Maniloff, 1992; Ludwig \& Schleifer, 1994; Farris et al., 1999). Despite intense debate (Ludwig \& Schleifer, 1994), a single method for phylogenetic reconstruction that can be used with complete confidence has not yet been identified. Therefore, in the current study, we used all four major algorithms to analyse the dataset (see Supplementary Table B in IJSEM Online). Consensus for spiroplasma groupings was obtained by using maximumparsimony analyses (See Figs 1-4).

Our trees varied somewhat in topology, not only among analytical methods, but also with choice of positions for analysis. Trees generated with $<1200$ positions tended to show suspiciously unusual groupings. Although we determined bootstrap values routinely, we are aware of some of the limitations of this analytical method. For example, the presence of uninformative characters may affect its utility (Carpenter, 1996). Some authors have discussed the influence of position choice on the topology of phylogenetic trees (Hansmann \& Martin, 2000). These authors point out that there is no a priori rationale for inclusion or exclusion of variable regions of a molecule, which, while difficult to align, may contain valuable phylogenetic signal. It is not clear why variable regions, if they can be aligned with reasonable certainty, should be excluded from analyses. In fact, when workers turn to analysis of the $16 \mathrm{~S}-23 \mathrm{~S}$ spacer region, variability is considered valuable for the resolution of intraspecific variability or variability among candidate members of very closely related species. Given the small evolutionary distances among some members of our strain complexes (e.g. serogroups I and VIII), an inclusionary strategy was followed in selecting the positions for most of our trees.

Under all these circumstances, results produced by trees generated under a wide range of assumptions offer important evidence. Support generated by the totality of the matrix of generated trees is important and where unanimous or nearly unanimous conclusions are reached, the phylogenetic inferences are surely robust.

\section{Problems in nomenclature of groupings}

Weisburg et al. (1989) named 'groups' by choosing a wellknown species that was represented in the clusters they obtained with their distance analyses. We use the term 'clade' rather than 'group' in this paper, as all of the groupings that we designate have been obtained or confirmed by maximum-parsimony analysis. Johansson \& Pettersson (2002) have followed Weisburg's precedent with considerable success; however, in our study, we found it difficult to adapt the existing nomenclature to certain clade structures.

One problem is that the concept of 'group' was first introduced into spiroplasma taxonomy (Junca et al., 1980; Bové et al., 1983; Whitcomb et al., 1987; Williamson et al., 1989) to denote putative species that were awaiting full characterization, according to proposed minimal standards 
(International Committee on Systematic Bacteriology Subcommittee on the Taxonomy of Mollicutes, 1995). In this paper, to avoid confusion between this conflicting usage of 'group', we use the term 'serogroup' to denote spiroplasma strain assemblages that were classified under this system. However, in addition, problems arose with attempts to adapt the historical group-cluster-subcluster terminology (Weisburg et al., 1989; Johansson \& Pettersson, 2002) to a rapidly growing array of mollicute taxa - the Apis clade.

All except one of the clades in the trees that we present here could be classified by Weisburg's group concept. Spiroplasma ixodetis could be easily designated as either a monospecific clade or group. Spiroplasmas in serogroups I and II or serogroup VIII, which each, respectively, form distinct clades, could be viewed as subclusters under the Weisburg nomenclature. Spiroplasma mirum, which we treat here as a monospecific clade, could be treated as a third subcluster of the spiroplasma group (sensu Weisburg et al., 1989). Also, the 18 species of Entomoplasmataceae and the five species of the M. mycoides cluster (which we show here to have clade status) could be classified as subclusters of Weisburg's ' $M$. mycoides cluster'. However, the remaining 26 Spiroplasma species, which we define herein to comprise the 'Apis clade sensu latu', are difficult to classify without creating either a large number of subclusters or none at all. Weisburg et al. (1989), who studied only six of these species, termed this grouping the 'Spiroplasma apis cluster'. However, as a result of discoveries of spiroplasmas in tabanids (Diptera: Tabanidae), mosquitoes (Diptera: Culicidae) and flower surfaces, the 'S. apis cluster' (which we show herein to have clade status) has now expanded to include 21 species that clearly fall within the topologic boundaries that were established by the Weisburg study. Five species sequenced in this study occupy topological positions and are moderately outside the original boundaries. Should the newly designated 'Apis clade' accrete these five species? In this paper, we have added these five species to the 21 species that can be assigned on the basis of their topological relationship to the Weisburg species set, to form an 'Apis clade sensu latu'. The clade, which consists of the 21 species that fit within the boundaries of Weisburg's concept, we term the 'Apis clade sensu strictu'. The designations 'latu' and 'strictu' are used commonly in taxonomy when group boundaries are redefined.

It was in the classification of the Apis clade that our ability to use the established 'group classification' vanished. We were unable to separate the 26 species of the Apis clade sensu latu into subclusters without considerable fragmentation. If this large clade had not been subdivided, however, a substantial number of clades with clear biological significance would have escaped naming. Subdivision into 'subclusters' fails in the Apis clade, as it must in many cases of rapid taxic expansion, in that by starting at the top of the hierarchical level with 'group', defining only 'cluster' and 'subcluster' beneath, one is likely - in large groups - to exhaust the available nomina before all useful subdividing has been accomplished. To impose this kind of nomenclature onto a phylogenetic classification duplicates one of the most serious shortcomings of Linnaean nomenclature: the imposition of a template on clade structures that are unsuited to it (see discussion on Linnaean classification versus phylogenetic classification). These comments should not be construed in any way as criticism of the classification of Johansson \& Pettersson (2002). Their useful classification represents the best possible attempt - in the interest of stability - to maintain the initial nomenclature of Weisburg et al. (1989) and has served well, even for the large and heterogeneous genus Mycoplasma. In summary, structural problems with clade topologies and the previous use of 'group' in Spiroplasma taxonomy in an entirely different sense make it difficult or impossible to use the 'group' concept for Spiroplasma clade nomenclature.

As noted in this paper, we approach nomenclature by defining clades. We use this term because all groupings to which we assign this term are derived from cladistic analyses (Swofford, 1998) - in most cases, maximum-parsimony. We also use the term 'clade' because the groups so defined will not be confused with any of the groups, clusters or subclusters of Johansson \& Pettersson (2002). However, the difference in nomenclature does not imply that the underlying tree structures are substantially different; in fact, in all cases where the trees of Johansson \& Pettersson (2002) and our trees describe the same species, the underlying topologies are quite similar and are sometimes identical.

\section{Clade nomenclature}

Clades mentioned in the text can be defined by referring to Tables 3 and 4 and Figs 1 and 2. Our nomenclatural approach differs from previous ones in that it starts not at a higher level, but at the level of the smallest clades, beginning with monospecific clades and clades that are composed of sister species. We present the data in this way as it is often clades of two to six species that are the most biologically and/or phenotypically significant. Our terminology uses: (i) lower-case species names (without italics) for clades with three or fewer species. For example, the sister species Spiroplasma lampyridicola and S. leptinotarsae form the lampyridicola-leptinotarsae clade. (ii) Clades with four or more species were named by using one or more of the component species, whose names served as nomina. These clades were named by using the single species name serving as the nomen, but in capital letters without italics. In Figs 1 and 2, we present phylogenetic trees that, with Tables 3 and 4 , show the clade labelling. As the discussions in this paper involve not only Spiroplasma clades, but also clades of Mollicutes at higher hierarchical levels, we have adopted the standard clade terminology for higher-level taxa shown in Fig. 1. (iii) Where higher-level clades are identified, we retain the initial capital letter of the Linnaean name and the Linnaean spelling of the taxon, not italicized.

Phylogenetic trees. In all, 23 trees were generated by maximum-parsimony, maximum-likelihood, neighbour-joining 
Table 3. Nomenclature for clades that represent higher hierarchical levels

\begin{tabular}{|c|c|c|}
\hline Clade & No. (nodes in Fig. 1) & $\begin{array}{l}\text { Synonymy with Weisburg et al. (1989) } \\
\text { and Johansson \& Pettersson (2002) }\end{array}$ \\
\hline Acholeplasmatales clade & 4 & A. laidlawii cluster \\
\hline Anaeroplasma clade & 3 & anaeroplasma group \\
\hline Asteroleplasma clade & 2 & asteroleplasma group \\
\hline Apis clade & 14 & apis cluster \\
\hline Citri-Chrysopicola-Mirum clade & 13 & citri cluster \\
\hline Hominis clade & 8 & hominis cluster \\
\hline ixodetis clade ${ }^{\star}$ & 12 & ixodetis cluster \\
\hline Mollicutes 'clade' $\dagger$ & 1 & Mollicutes \\
\hline Mycoides-Capricolum-Putrefaciens clade & 16 & mycoides cluster \\
\hline Mycoides-Entomoplasmataceae clade & 15 & mycoides cluster \\
\hline Mycoplasmatales-Entomoplasmatales clade & 6 & None \\
\hline Phytoplasma clade & 5 & Candidatus Phytoplasma cluster \\
\hline Pneumoniae clade & 9 & pneumoniae cluster \\
\hline Pneumoniae-Hominis-Ureaplasma-Haemoplasma (PHUH) clade & 7 & None \\
\hline Spiroplasma-Entomoplasmataceae-Mycoides (SEM) clade & 11 & None \\
\hline Ureaplasma clade & 10 & ureaplasma cluster \\
\hline
\end{tabular}

*This clade is in lower case because it is monospecific.

$\dagger$ Mollicutes, according to most phylogenetic reconstructions.

and distance (Supplementary Table B, available in IJSEM Online). Two of these trees are presented herein: Fig. 3 is a parsimony majority-rule consensus tree and Fig. 4 shows the same dataset with bootstrap values included (500 replicates).

\section{Highly supported features of spiroplasma trees}

The fundamental premise of cladistic taxonomy is that appropriate analyses will yield nested clusters (clades) of taxa that, having arisen from a single ancestor, share a common heritage. Twenty-four such clades are supported strongly by our studies, in that they occur in all, or almost all, trees constructed, regardless of the algorithm used in the analysis, and are usually afforded high support in bootstrap analyses. Supplementary Table B (available in IJSEM Online) lists the fraction of the 23 trees analysed that support each clade. In the following section, we list these highly supported clades and features and briefly discuss the biological characteristics of the clades that they define.

\section{Monophyly of the Mycoplasmatales-Entomoplasmatales} clade of Mollicutes. The orders Mycoplasmatales and Entomoplasmatales form a clade that is a sister to the Acholeplasma-Anaeroplasma-Phytoplasma clade of Mollicutes. The order Mycoplasmatales is polyphyletic, in that Mycoplasma species are split into two phylogenetically separate sections that do not share a common ancestor. Nevertheless, the two orders, taken together, are shown herein to have derived from a single common ancestor. Unlike most other prokaryotes, members of the Mycoplasmatales-Entomoplasmatales clade - so far as is known - use UGA as a codon for tryptophan and not as a stop codon. This character, although it has not been determined for most mollicutes, has been hypothesized to be synapomorphic for the Mycoplasmatales-Entomoplasmatales clade. Although this clade has no formal recognition in Linnaean taxonomy, it represents a profound split in the mollicute lineage and may have diverged from an ancestral lineage hundreds of millions of years ago (Hackett, 1990; Hackett et al., 1990; Maniloff, 2002).

Position of the Spiroplasma-EntomoplasmataceaeMycoides grouping (SEM) clade as a sister lineage to the Pneumoniae-Hominis-Ureaplasma-Haemoplasma (PHUH) clade. As in other trees that represent mollicute phylogeny [reviewed by Johansson \& Pettersson (2002)], our trees showed consistently that the paraphyletic SEM clade is a sister lineage to a large, also paraphyletic, clade (PHUH) that contains over 100 species of Mycoplasma, including the (paraphyletic) Pneumoniae clade, the Hominis clade, ureaplasmas and haemoplasmas. Mycoplasma species of this clade form a paraphyletic unit that has no Linnaean designation, but given its origin from a common ancestor, should be treated as monophyletic for purposes of binomial nomenclature. The Pneumoniae clade (e.g. Mycoplasma pneumoniae, Mycoplasma genitalium, Mycoplasma iowae and Mycoplasma pirum) has many species in which cytoskeletal modifications, including terminal blebs, are present. This technically paraphyletic clade contains the ancestral root of the genus Ureaplasma, an apomorphic taxon that presumably arose by transfer of a lineage of the Pneumoniae clade into the urogenital tract of vertebrates. The Pneumoniae clade also is the ancestral root of 'haemoplasmas' (Neimark \& Kocan, 1997), a 
Table 4. Clade nomenclature

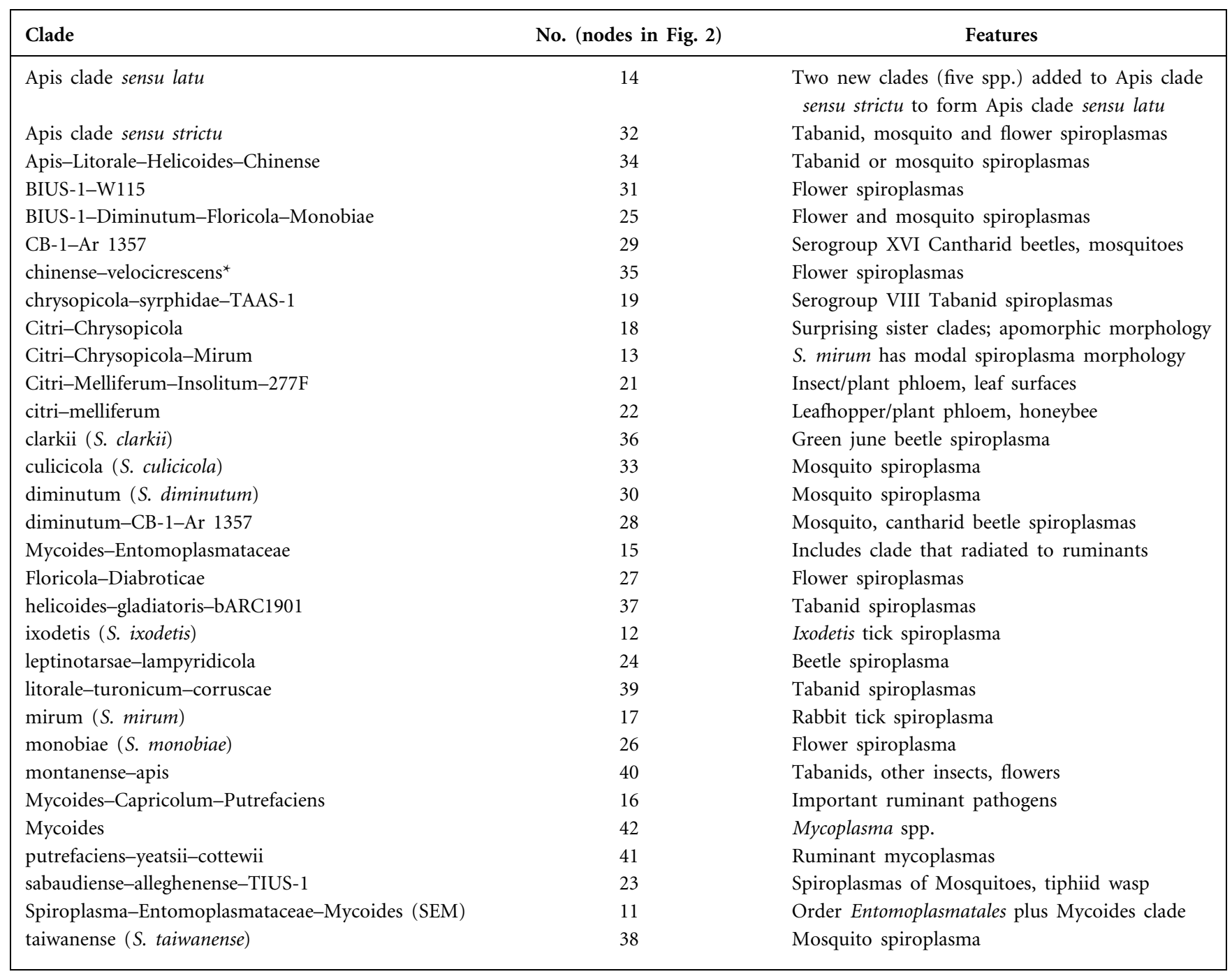

${ }^{\star}$ Clade names with three or fewer species are not capitalized.

trivial name that was proposed by Neimark et al. (2001) for a cluster of haemophilic mycoplasmas, which had been named before the general concept of Candidatus status had been proposed (Murray \& Stackebrandt, 1995). Haemoplasma species have recently been transferred to the genus Mycoplasma (Neimark et al., 2001).

\section{Position of the Mycoides clade within Entomoplasmatales.} Here, we confirm and extend, by addition of 26 new complete Spiroplasma sequences (designated by GenBank accession numbers starting with AY in Table 2), the reports of others (Weisburg et al., 1989; Maniloff, 1992; Gundersen et al., 1994; Johansson \& Pettersson, 2002) that M. mycoides and four allied Mycoplasma species, together with the Entomoplasmataceae clade, with which it has a sister relationship, comprise an evolutionary terminus that is derived from a spiroplasmal ancestor.
Together, these groupings comprise the MycoidesEntomoplasmataceae clade. Our trees demonstrate that the Mycoides clade is apomorphic in this clade of 23 species. Derivation of the Mycoides clade from the Entomoplasmataceae renders this family technically paraphyletic. We use the word 'technically' because we regard an emphasis on paraphyly as detrimental to the quest for groupings of species with common ancestors. The fact that a lineage has split off from an otherwise cohesive clade, in our view, does nothing to alter the evolutionary history of the clade itself or to change its status as having arisen from a common ancestor. Hence, realizing that not all systematists agree with us, we have chosen to note paraphyly without proposing it to be a nomenclatural determinant in Linnaean systems. It is polyphyly, not paraphyly, that threatens the utility of Linnaean classifications. The Mycoides-Entomoplasmataceae clade is a sister lineage to the Apis clade sensu latu, which is shown here 


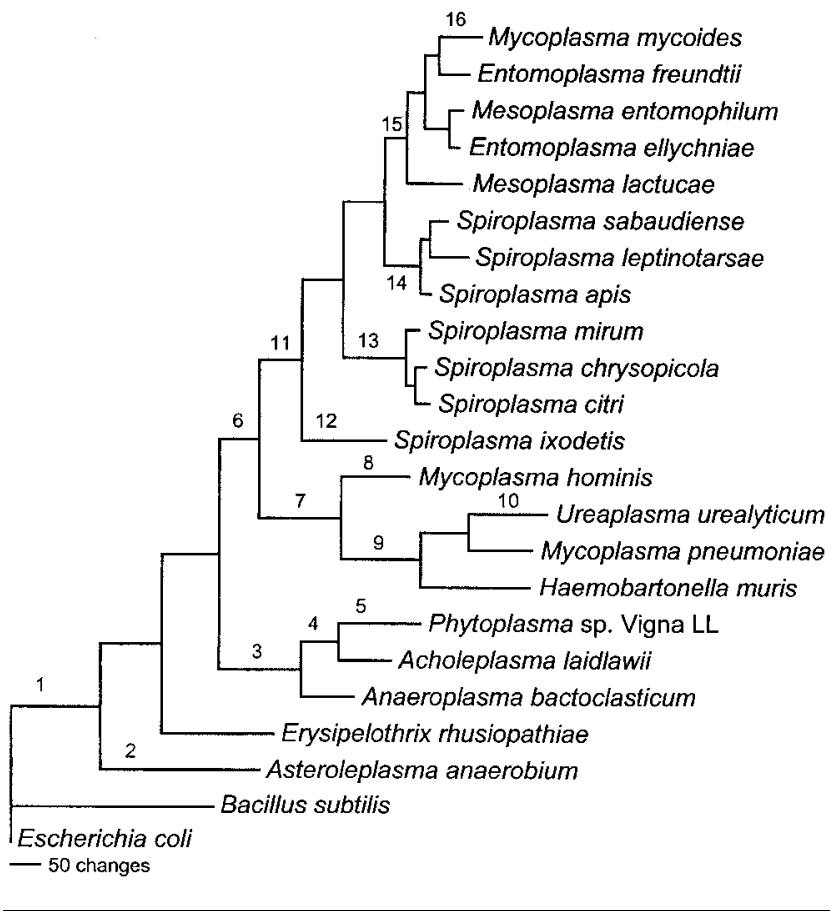

Fig. 1. Phylogram showing positions of clades at higher-level hierarchies of Mollicutes. See Table 3 for synonymy of clades described herein with the groups, clusters and subclusters of Weisburg et al. (1989) and Johansson \& Pettersson (2002). to contain the 21 species (or putative species) of the Apis clade sensu strictu [the six species analysed by Weisburg et al. (1989) plus 15 spiroplasmas sequenced herein, whose phylogenetic position falls within the boundaries established by that study] plus two novel clades (the lampyridicola-leptinotarsae and sabaudiense-alleghenenseTIUS-1 clades), which together have a total of five species, all topologically placed outside the original group boundaries; thus, there are 26 spiroplasmas in the Apis clade sensu latu. Both novel clades are basal to the Apis clade sensu strictu and are thus related more closely to the Entomoplasmataceae and M. mycoides than members of the Apis clade sensu strictu. The discovery of other spiroplasmas that are related more closely to M. mycoides than those previously known enables us to better evaluate the relationship of the Mycoides clade (and its sister, the Entomoplasmataceae clade) to spiroplasmas.

Essential monophyly of Spiroplasma and subdivision of the SEM clade. All currently classified Spiroplasma species form a single evolutionary unit that is derived from a common ancestor. As explained above, we do not believe that the status of Spiroplasma as being technically paraphyletic should be considered in the construction of Linnaean classifications. All trees and bootstrap values for the major nodes strongly support the subdivision of this clade into the ixodetis clade, the Citri-Chrysopicola-Mirum

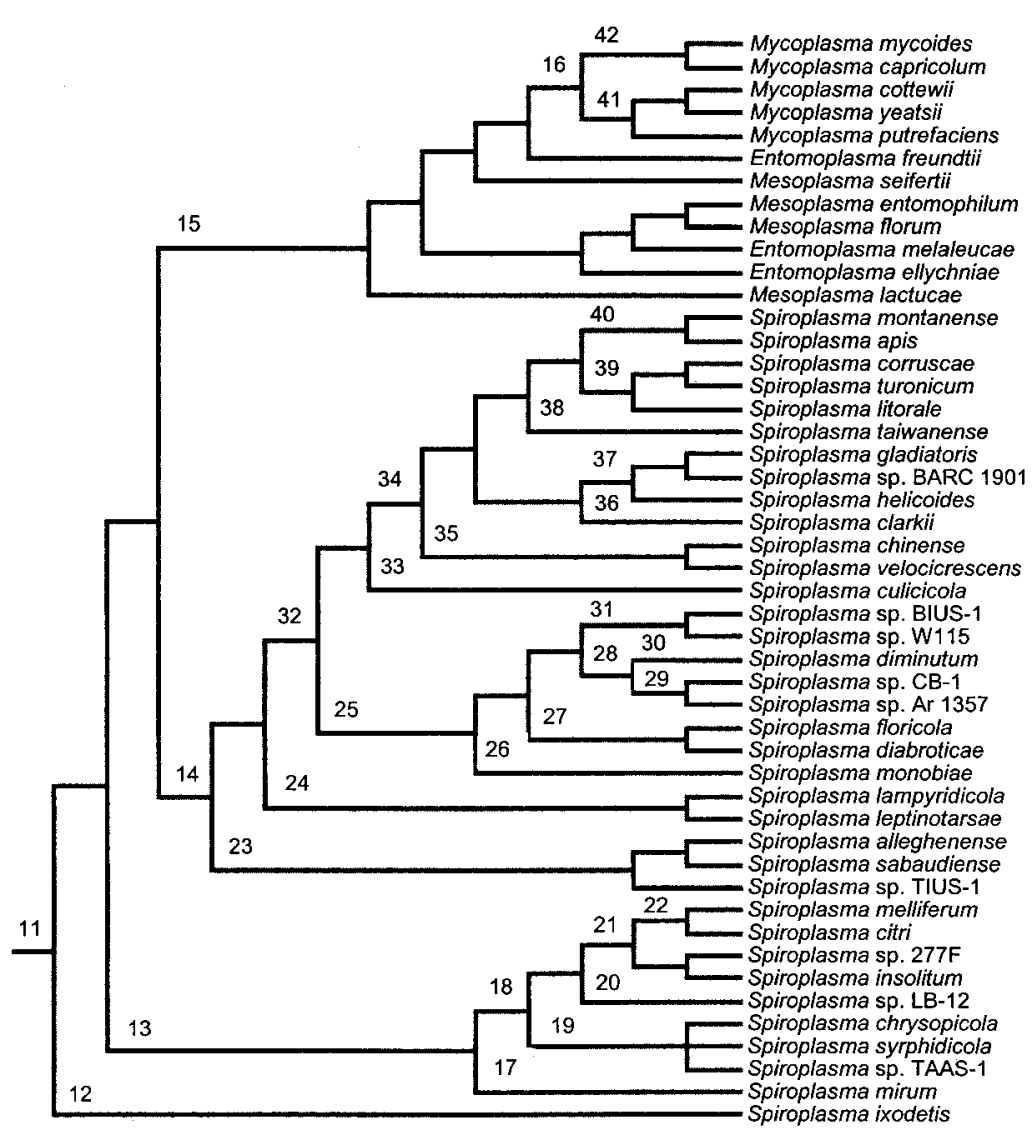

Fig. 2. Majority-rule maximum-parsimony tree showing position of major clades of the Spiroplasma-Entomoplamataceae-Mycoides (SEM) clade. Note that Spiroplasma is, technically, paraphyletic. See Table 4 for clade information. 


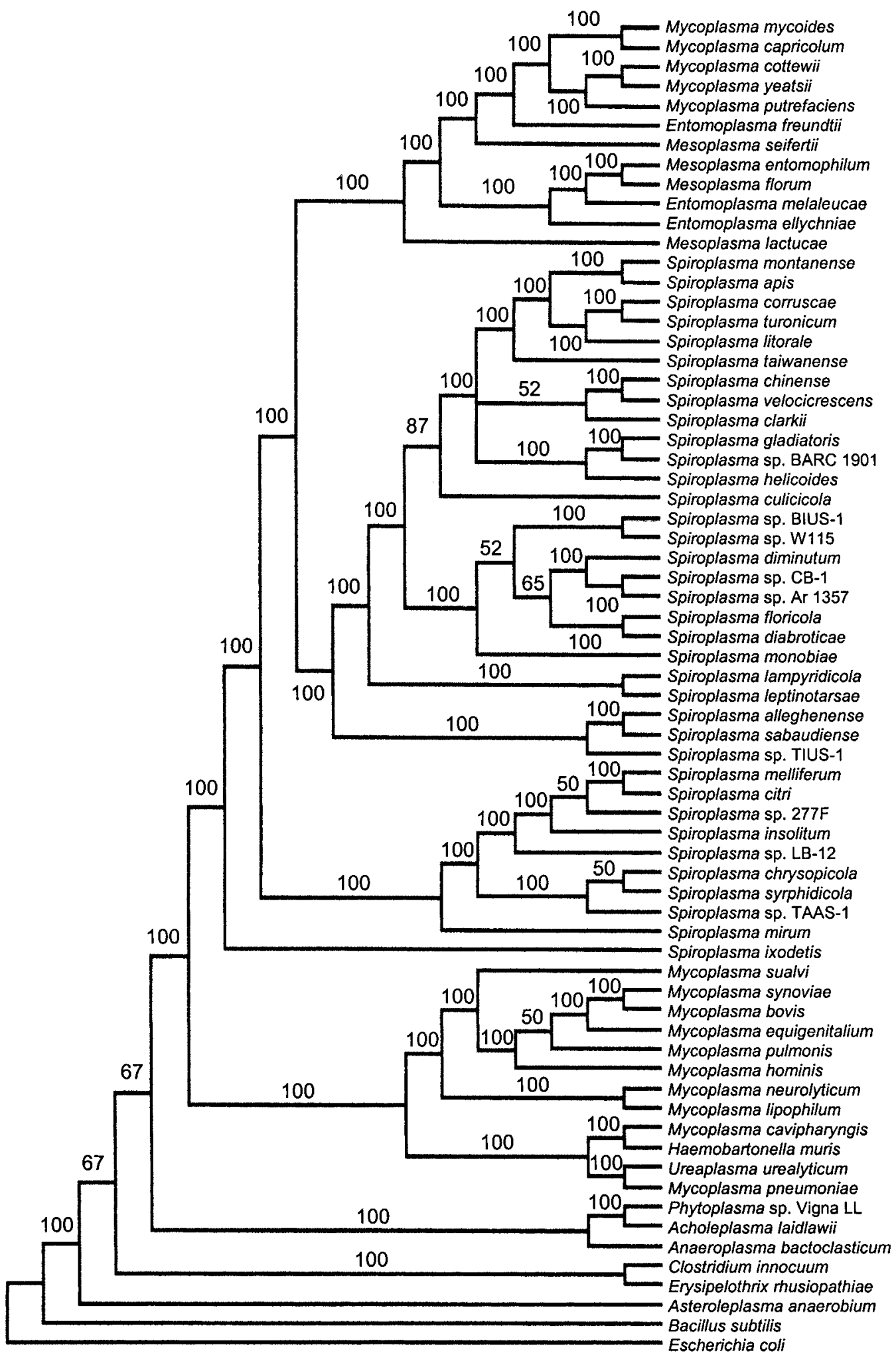

Fig. 3. Phylogenetic reconstruction using maximum-parsimony. Four Gram-positive bacterial species and Escherichia coli served as outgroups. Analysis was confined to those positions in the alignment that satisfied the condition that one base accounts for at least $50 \%$ of the total composition of that position (a total of 1428 characters). The analysis used a heuristic search and the tree bisection-reconnection maximum-parsimony algorithm for branch-swapping. Note: Phytoplasma is a Candidatus genus designation. 


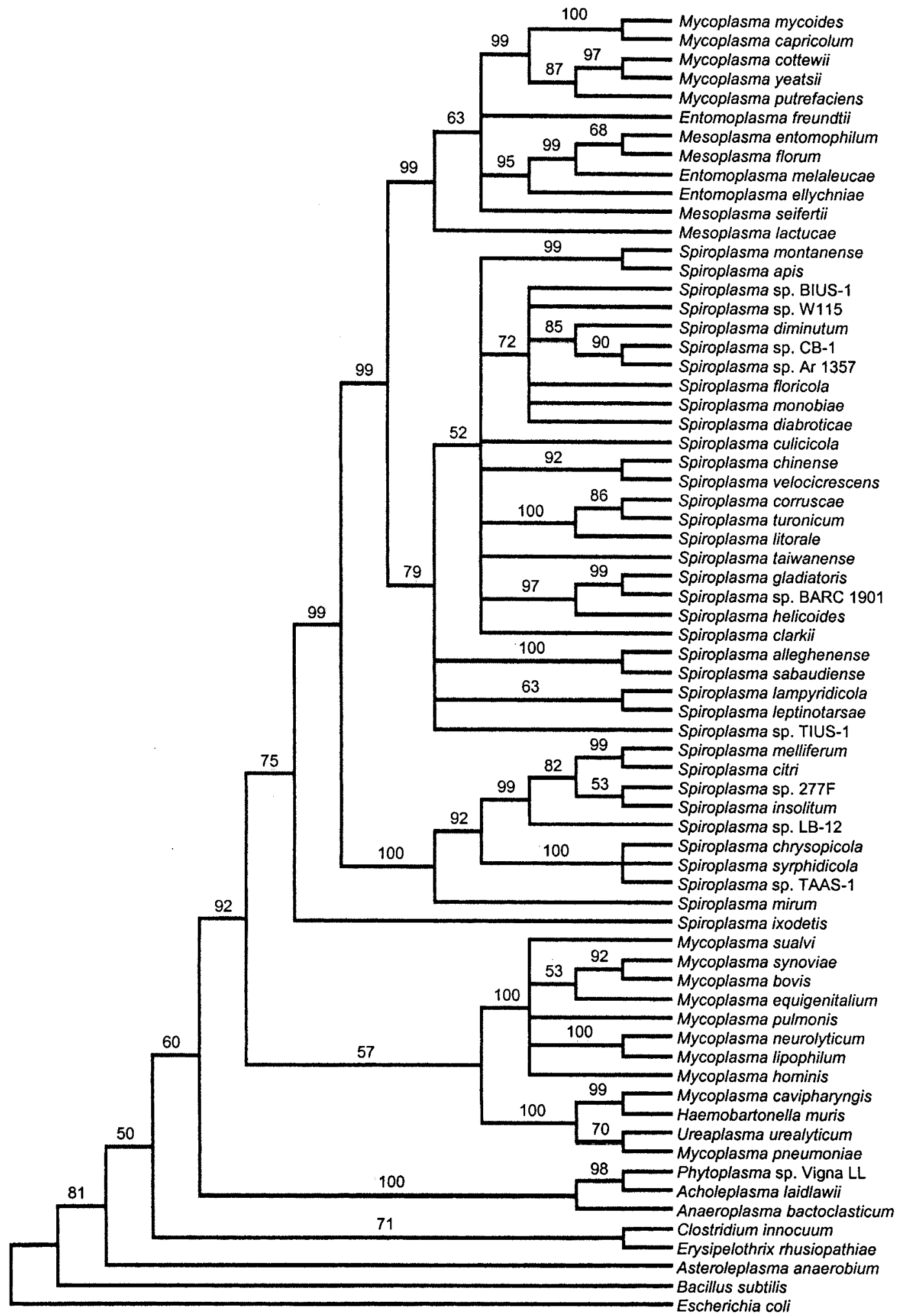

Fig. 4. Phylogenetic tree showing the position of the class Mollicutes and representative members of the phylum Firmicutes. Escherichia coli and three Gram-positive bacteria served as outgroups. In total, 1428 positions were used in the analysis, with the tree bisection-reconnection maximum-parsimony algorithm for branch-swapping. The dataset was resampled 500 times; bootstrap percentage values are given at nodes. Note: Phytoplasma is a Candidatus genus designation. 
clade, the Apis clade sensu latu and the MycoidesEntomoplasmataceae clade.

The ixodetis clade is basal in the spiroplasma lineage. The ixodetis clade diverges at the base of the Spiroplasma evolutionary tree. Originally, this clade was thought to consist of a single species, S. ixodetis (serogroup VI) and, technically, it still does. However, there have been several recent claims that certain micro-organisms that are associated with insects cluster with $S$. ixodetis. In each case, evidence consists of the $16 \mathrm{~S}$ rDNA sequence similarity of the candidate organisms to spiroplasmal DNA of S. ixodetis, as revealed by BLAST searches. It should be noted that BLAST searches may not reveal the nearest neighbour and are by no means final arbiters of phylogenetic position (Koski \& Golding, 2001). Also, in no case were micro-organisms envisioned or cultured. In some cases (Hurst et al., 1999; Hurst \& Jiggins, 2000; Jiggins et al., 2000), organisms were reported to be associated with sex-ratio abnormalities in coccinellid beetles (Adalia bipunctata) or a butterfly (Danaus chrysippus) (Jiggins et al., 2000). A publication from Russia (Sokolova et al., 2002) reported electron microscopic visualization of spiroplasmas in ovarioles of A. bipunctata. The structures depicted appear to be filamentous, but do not display clear helicity. There is no way of knowing whether the envisioned organisms are actually spiroplasmas and, if so, whether they represent the Adalia sex-ratio agent. In any event, phylogenetic placement of the Adalia agent is problematical, especially when one considers that the taxic sampling used in phylogenetic analyses concerning them was extremely limited. Other isolates with an apparent topological relationship were from the bamboo pseudococcid (Fukatsu \& Nikoh, 2000) and green pea aphid (Fukatsu et al., 2001). The affinity of these hypothetical 'group members' to $S$. ixodetis must be examined in the context of long-branch attraction (Carmean \& Crespi, 1995; Siddall \& Whiting, 1999; Stiller \& Hall, 1999). S. ixodetis exhibits an unusual, tightly coiled helicity, whereas other spiroplasmas display a less tightly coiled helicity. Whether this morphology is apomorphic or plesiomorphic for spiroplasmas is at present unknown. Detailed study of the cytoskeletal structure of spiroplasmas suggests that helicity itself is a fundamental condition that can be modified without substantial genomic change (Trachtenberg \& Gilad, 2001; S. Trachtenberg, personal communication). The $S$. ixodetis genome is $2220 \mathrm{kbp}$ in size, which is the largest in the genus Spiroplasma and just $500 \mathrm{kbp}$ smaller than the genome of Acholeplasma laidlawii. However, the complete genome sequence of $S$. ixodetis has not been determined, so we do not know how much of this genome represents ORFs or, alternatively, repeat sequences or integrated viral or plasmid DNA, which represent a substantial portion of some spiroplasmal genomes (U. Melcher, personal communication).

Monophyly of the Citri-Chrysopicola-Mirum clade. High support is accorded to the monophyly of the clade
Citri-Chrysopicola-Mirum, which contains serogroup I and II spiroplasmas (Citri-Poulsonii clade), serogroup VIII spiroplasmas (chrysopicola-syrphidicola-TAAS-1 clade) and the mirum clade [S. mirum (serogroup V)], despite the substantial phenotypic differences that characterize each of these three component clades. Given the conspicuous phenotypic and genotypic differences between the Chrysopicola-Syrphidicola-TAAS-1 and CitriPoulsonii clades, their sister status is surprising.

Monophyly of the Citri-Poulsonii clade. High support is obtained for the clade (Citri-Poulsonii) that contains the seven sequenced serogroup I spiroplasmas and the serogroup II species Spiroplasma poulsonii. Serogroup I spiroplasmas form an ecologically diverse cluster that has been divided into eight subgroups on the basis of serology and DNA-DNA reassociation (Junca et al., 1980, Bové et al., 1983). In this paper, we include in our trees only five of the eight sequenced members of the CitriPoulsonii clade; S. poulsonii, Spiroplasma phoeniceum and $S$. kunkelii, which have been sequenced, are not represented in Figs 3 or 4, and strain N525, the representative strain for subgroup I-7, has not been sequenced. Trees for the Citri-Poulsonii clade that contained all eight available sequences showed some minor inconsistencies in their topologies. We have chosen to omit the three sequenced species from the trees we present here, as topologies for this group have not yet been resolved completely. Of course, the small inconsistencies observed in internal topology do not negate the integrity of the clade itself. It is to be expected that the nodes of the serogroup I cluster should be difficult to resolve (Stackebrandt \& Goebel, 1994), as the similarity coefficients of their $16 \mathrm{~S}$ rDNA sequences ranged from 0.986 to 0.991 .The Citri-Poulsonii clade is of great interest, in that it has a wide diversity of spiroplasma-host associations. Members of this cluster occur in ticks, honeybees, leafhoppers (plant phloemsucking insects), plant/flower surfaces and Drosophila, in which they cause sex-ratio abnormalities (Williamson \& Poulson, 1979; Williamson et al., 1989). Given these host relationships, each node in the Citri-Poulsonii clade is of critical importance.

Basal position of subgroup I-5 spiroplasmas in the Citri-Poulsonii clade. The basal position of subgroup I-5 strain LB-12 and its allies is supported by all topologies we obtained for the Citri-Poulsonii clade. This spiroplasma was isolated from the green leaf bug in Taiwan (Lei et al., 1979). As noted in the section on Evolution, this position is critical, as it implies that the plesiomorphic habitat in the Citri-Poulsonii clade may have been the plant phloem/sucking insect habitat.

Position of subgroups I-4 and I-6 as sister species in the Citri-Poulsonii clade. Strain 277F, the sole member of subgroup I-4, and subgroup I-6, represented by Spiroplasma insolitum, were classified as sister species in all topologies. Although strain $277 \mathrm{~F}$ was isolated from a 
tick, only a single strain is available, so the true habitat relationship of this spiroplasma is uncertain. S. insolitum has been isolated frequently from flowers and insects, including butterflies, in Maryland, USA (Hackett et al., 1984).

Monophyly of the chrysopicola-syrphidicola-TAAS-1 clade. Spiroplasma chrysopicola, Spiroplasma syrphidicola and Spiroplasma sp. TAAS-1 (serogroup VIII) always formed a monophyletic clade. In addition, strains BARC 1357 and BARC 2649, candidate subgroups of serogroup VIII, also belong to this clade. However, the evolutionary distances among these five serogroup VIII strains are very small (16S rDNA similarity coefficients of 0.992-0.999) so these sequences failed to resolve the relationships among them (G. E. Gasparich, unpublished data), as would be expected (Stackebrandt \& Goebel, 1994). Members of the chrysopicola-syrphidicola-TAAS-1 clade have been isolated almost exclusively from tabanid flies. Members of this group are, physically, the smallest spiroplasmas passing quantitatively through $220 \mathrm{~nm}$ filters. This group also has a DNA G + C content $(28-31 \mathrm{~mol} \%)$ at the high end of the spiroplasma range and all members utilize arginine. More than 100 serogroup VIII isolates have been obtained from eastern Canada, south to Georgia, west to Idaho and Texas. The group is also known from Europe (Le Goff et al., 1991). Recently, more than a dozen isolates have been obtained, ten from Costa Rica and three from Australia (F. E. French, unpublished data). Three formal subgroups have been proposed for serogroup VIII strains on the basis of DNA-DNA hybridization, DNA G+C content and serological analyses (Gasparich et al., 1993). Type or representative strains are: EA-1 (S. syrphidicola, subgroup VIII-1); DF-1 (S. chrysopicola, subgroup VIII-2) and TAAS-1 (subgroup VIII-3). In addition, strain BARC 2649 was classified by Williamson et al. (1998) as an undesignated subgroup of serogroup VIII. However, as new isolates continue to accumulate, it has become more and more difficult to assign them to a subgroup (Stewart, 2001; F. E. French and R. F. Whitcomb, unpublished data).

Position of $S$. mirum as basal in the CitriChrysopicola-Mirum clade. The phylogenetic position of the tick spiroplasma, S. mirum, as basal in this clade of insect specialists was highly supported. S. mirum is the most basal species of Spiroplasma that shows the modal spiroplasma helicity and motility.

Position of the Mycoides and Entomoplasmataceae clades as sister lineages. High support is obtained for the apomorphic status of the Mycoides clade as a derivative of the Entomoplasmataceae clade. Hence, the taxon Entomoplasmataceae is technically paraphyletic. Mesoplasma lactucae was basal to the Entomoplasmataceae clade and Entomoplasma freundtii was basal to the Mycoides clade. As discussed below, divergence of the Mycoides and Entomoplasmataceae clades is in complete accord with the host affinities of the organisms. All species of the Mycoides clade are from ruminant animals and all entomoplasmas and mesoplasmas derive from the insect/plant surface habitat.

Polyphyly of Entomoplasma and Mesoplasma species. All trees constructed to date, starting with the original distance trees of Weisburg et al. (1989) and including later trees of Johansson [summarized by Johansson \& Pettersson (2002)] and Maniloff (2002) have indicated that species of the genera Mesoplasma and Entomoplasma do not form clades, but are intermixed, with small interspecies evolutionary distances. Our trees also fail to show distinct clusters for these genera. Furthermore, the similarity coefficients for $16 \mathrm{~S}$ rDNA sequences are extremely high in some intergeneric comparisons [Entomoplasma melaleucae versus Mesoplasma entomophilum (0.992)].

The two serogroup XVI species studied are sisters. Strains CB-1 (subgroup XVI-2) and Ar 1357 (subgroup XVI-3) were shown invariably to be sisters in the cladograms. Members of this serogroup are either isolates from flower surfaces or from cantharid beetles, which are frequent visitors of flowers. Several isolates in this clade have also been isolated from mosquitoes. The third subgroup, Spiroplasma cantharicola (XVI-1), was not sequenced in this study, but DNA-DNA hybridization data (AbalainColloc et al., 1993) indicate that this species is related closely to subgroups XVI-2 and XVI-3.

Sister taxa status of serogroup XVI spiroplasmas and Spiroplasma diminutum. All trees showed S. diminutum and the CB-1-Ar 1357 (serogroup XVI) clade as sister lineages. However, S. diminutum is not related serologically to serogroup XVI spiroplasmas. S. diminutum and certain serogroup XVI strains have been isolated from mosquitoes.

Monophyly of the helicoides-gladiatoris-BARC 1901 clade. This clade of three species (or putative species), all isolated from tabanid flies, was highly supported in trees generated by all four phylogenetic methods.

Monophyly of the corruscae-turonicum-litorale clade. The monophyly of these three tabanid Spiroplasma species was also supported strongly. Spiroplasma corruscae was originally isolated from an overwintered lampyrid beetle, which has raised the issue of transmission and maintenance of the spiroplasma during winter (Hackett et al., 1996b). It is possible that beetles provide an overwintering reservoir for $S$. corruscae and that tabanids acquire the spiroplasma in the spring at feeding sites that are shared with the beetles (Gasparich et al., 1998).

Status of S. apis and Spiroplasma montanense as sister species. These sister species formed a clade (apismontanense clade) that was separated from other tabanid spiroplasma clades by relatively small evolutionary distances. Both species have been isolated from tabanids, but 
S. apis causes May Disease of honey bees in France and has been isolated from other insect host species.

\section{Sister lineage status of serogroups XXI (strain W115)} and XXX (strain BIUS-1) flower spiroplasmas. These two spiroplasmas were sister species in most trees. Strains W115 and BIUS-1 were respectively isolated from flower surfaces in Oklahoma and Maryland, USA, so the actual (presumed) insect hosts of these species is unknown.

Position of S. lampyridicola and S. leptinotarsae as sisters. These sister species are both beetle spiroplasmas. $S$. leptinotarsae is a specialist that is associated with the Colorado potato beetle (Clark, 1982) and S. lampyridicola is a specialist that is associated with firefly beetles (Coleoptera: Lampyridae), respectively (Clark et al., 1987; Hackett et al., 1992; Stevens et al., 1997). S. leptinotarsae is transmitted from beetle to beetle on leaf surfaces (Clark, 1984). The unusual morphology of this species is discussed in the Morphology section. S. lampyridicola has been isolated from both larvae and adult fireflies, but the transmission mechanism is unknown. Cells of this spiroplasma are unusual in that, when tested as an antigen, they react serologically in both deformation (DF) (Williamson et al., 1978) and metabolism inhibition (MI) (Williamson et al., 1979a) tests with the majority of spiroplasma antisera. Cells of S. leptinotarsae, when tested as antigens, also react with multiple spiroplasma antisera. Whether this property is synapomorphic for the leptinotarsae-lampyridicola clade is unknown.

Position of Spiroplasma sabaudiense (serogroup XIII), Spiroplasma alleghenense (serogroup XXVI) and Spiroplasma sp. strain TIUS-1 (serogroup XXVIII) as a monophyletic clade. The sabaudiense-alleghenenseTIUS-1 clade, which appeared in most trees, makes less ecological sense than most of the other spiroplasma clades. It consists of serogroups XIII, XXVI and XXIX, which have been isolated from a diverse range of insects, including mosquitoes (postulated to feed on flowers) (Chastel \& Humphery-Smith, 1991) and flower-visiting tiphiid wasps, as well as scorpionflies.

\section{Phylogenetic classification and phenotype}

Phylogenetic reconstructions have at least three practical uses. The first is to predict or anticipate the properties of organisms that have yet to be determined. The second is to shed light on the evolutionary process itself, which must be understood in order to make sense of biology. The third is guidance in construction of Linnaean classifications, so that the latter may reflect, as closely as possible, the natural relationships among taxa.

Previous authors, after examination of the relationship between mollicute phylogeny and phenotype, painted a rather bleak picture. Weisburg et al. (1989), whilst acknowledging that some correlations between phylogeny and phenotype were apparent ex post facto, felt that phenotype was not well predicted by phylogeny. Also, Dodge et al. (1998) felt that their phenetic tree showed that serological analysis of spiroplasmas was unreliable. Our trees and phenotypic data support neither of these views.

The study of Weisburg et al. (1989), which still stands as a defining paper on mollicute phylogeny, dealt with a relatively small sample of available organisms, which were chosen because they were perceived to represent a wide spectrum of mollicute biodiversity. Thus, they were chosen because they were likely to be members of diverse clades that were phylogenetically remote from one another and, hence, less likely to be phenotypically similar than species that were more closely related. Many microbial phenotypic properties are apomorphic traits that are only shared with closely related species and often converge despite phylogenetic disparity.

In the analysis of Dodge et al. (1998), weight was given to a sequence whose placement was suspiciously anomalous. The value of serology was discounted in large part, as one unsubstantiated sequence for strain TAUS-1 (Spiroplasma tabanidicola) appeared to be related closely to sequences of spiroplasmas in the chrysopicola-syrphidicola-TAAS-1 clade. If this relationship were genuine, it would not only fly in the face of strong serological evidence, but also would contradict the seemingly unerring congruence of spiroplasma serology with DNA-DNA reassociation data (Junca et al., 1980; Bové et al., 1983). Further, it would imply that extremely short and narrow organisms with a relatively high DNA $\mathrm{G}+\mathrm{C}$ content and the ability to catabolize arginine aggressively were related extremely closely to spiroplasmas that were relatively long and wide with a considerably lower $\mathrm{G}+\mathrm{C}$ content and with no capability to catabolize arginine. Thus, the rejection of serological evidence in the systematics of these organisms on the basis of an aberrant placement of a single sequence would require one to ignore a suite of robust characters that separate the chrysopicola-syrphidicolaTAAS-1 clade from the Apis clade sensu latu.

Morphology. Morphology is a primary descriptor in most classifications of animals and plants; it is also important among microbes. Spiroplasma morphologies were not analysed herein as characters, because some distinctions are somewhat arbitrary. However, the consistency of morphology with cladistic topology is striking and must be discussed, even if it is not analysed rigorously. It is common for spiroplasma clades to share a common apomorphic - and in many cases, autapomorphic - set of morphological attributes. The following discussion refers to morphology as viewed microscopically during growth of the organisms in culture. The following morphotypes can be recognized.

(i) In the Citri-Poulsonii (serogroup I-serogroup II) clade, organisms are seen, after elongation of short forms during very early exponential phase, as long helices (10 or more turns) (Garnier et al., 1984). This morphology remains 
stable throughout the exponential and early stationary growth phases.

(ii) In the chrysopicola-syrphidicola-TAAS-1 (serogroup VIII) clade, organisms grow very fast to titres as high as $10^{11}$. Cells are short and narrow and can pass quantitatively through $220 \mathrm{~nm}$ filters. This morphology and the high titre to which cultures grow are diagnostic and, in routine screening, it is often possible to test candidate serogroup VIII strains against the bank of serogroup VIII antisera without preliminary screening against antiserum to organisms of other spiroplasma groups (Whitcomb \& Hackett, 1996). Also, the vast majority of the serogroup VIII isolates $(>100)$ have short cells, although in a few strains, longer cells have been observed (F. E. French, unpublished data).

(iii) Most spiroplasmas of the Apis clade sensu strictu tend to resemble those of the Citri-Poulsonii clade in their helicity, but are usually shorter. This morphology is presumably plesiomorphic in the clade and perhaps even in the genus (see Evolution). Some of the members of the clade (e.g. Spiroplasma helicoides) exhibit robust helical morphology that remains uncompromised throughout the exponential and early stationary growth phases.

(iv) Some species of the Apis clade sensu latu show autapomorphic modifications of simple helicity. In S. leptinotarsae, the cells are funnel-shaped, in that they are broad at one end but narrow to a tip at the other, with increasing amplitude from the tip to the posterior end of the cell when observed in early passages. In vitro, these cells exhibit extremely rapid translational motility. In vivo, in the gut of the host (the Colorado potato beetle), the helical cells flatten into a single plane, so that transverse sections show coiled tubules. Under dark-field microscopy, these structures appear to be coin-shaped. When these flattened coils are released into fresh culture medium, the cells regain their funnel (or spring-like) morphology and are again capable of rapid translational motility. As spectacular as this morphological adaptation is, it is ephemeral. In primary culture, $S$. leptinotarsae grows very poorly in artificial media, but cultures can be established in co-cultures with insect cells. After a relatively short number of passages in broth media, the ability to form helical cells with continuously varying helical amplitudes disappears and the cells then revert to simple helicity [see (iii) above].

(v) Some members of the BIUS-1-Floricola-DiabroticaeMonobiae clade of the Apis clade sensu strictu have short cells that may be helical at only certain phases of the growth cycle. Spiroplasma floricola (serogroup III) grows very rapidly in the exponential phase as short helices, but as the medium acidifies and is deprived of nutrients by the rapidly growing organisms, the cells become non-helical. For a short period, these non-helical cells, if they are reinoculated into fresh medium, are able to grow and helical morphology reappears (Whitcomb \& Coan, 1980). In serogroup XXX (strain BIUS-1), the morphological cycle in vitro is somewhat similar, although helices appear for a short time only in mid-exponential phase. Cells of either S. floricola or strain BIUS-1, if examined superficially and viewed only in stationary phase, might appear to be non-helical and could conceivably be mistaken for entomoplasmas. In fact, when strain BNR1 of $S$. floricola was first isolated and passed in the laboratory, it was mistaken for a non-helical organism, but when examined in exponential phase, it was found to exhibit swarms of short helical cells (D. L. Williamson and R. F. Whitcomb, unpublished data). S. diminutum, although allied closely to the CB-1-Ar 1357 clade, in which cellular morphology is unremarkable, grows prolifically as extremely short cells, with perhaps no more than two or three turns per cell. Spiroplasma culicicola, a species of the Apis clade sensu strictu that has no close sister species, also grows as very short cells with few turns. As all spiroplasmas that have very short cells have rapid growth rates, it is possible that the tendency for short cells may be explained by the rapidity of cellular growth.

(vi) Strain TIUS-1 (serogroup XXIX) exhibits such poor helicity in culture that it could easily be mistaken for an entomoplasma. Helical forms are rarely seen in culture. This species is basal to the apis clade sensu latu and, evolutionarily, may represent a transitional morphological stage in the loss of helicity.

Three spiroplasma species show autapomorphic adaptations that involve a departure from simple generic modal helicity: (vii) S. ixodetis has cells that are extremely variable in culture. Some of them are not helical and some have extremely tightly coiled helices - so much so that under dark-field microscopy, they may not appear helical at all. (viii) Serogroup XV spiroplasmas, the $16 \mathrm{~S}$ rDNA of which was not sequenced, lose helicity and motility and become stiff and rod-like as the growth medium acidifies in late exponential phase. However, if the $\mathrm{pH}$ of the medium is raised to neutral, helicity and motility return. (ix) Spiroplasma platyhelix, the $16 \mathrm{~S}$ rDNA of which was also not sequenced, displays a low-pitch helical morphology and, along with serogroup XV spiroplasmas, exhibits a unique motility, in which tightly coiled segments move in waves along the length of the filament.

In summary, there are many modifications of the simple helicity that is exhibited by species of the Apis clade sensu strictu. In many cases, these modifications are synapomorphic for clades of closely related species. However, several are autapomorphies and thus do not provide phylogenetic information.

Serology. Careful examination of the totality of spiroplasma data indicates a strong correlation between serology and molecular phylogeny. Serology of spiroplasmas has been studied in great detail [summarized by Williamson et al. (1998)] by the spiroplasma DF (Williamson et al., 1978) and MI (Williamson et al., 1979a) tests, and by growth inhibition (Whitcomb et al., 1982) for serogroups I-XI. Serogroup classification of 
spiroplasmas (Junca et al., 1980; Whitcomb et al., 1987) is based to a considerable degree on serological data. Minimum standards have been established for the serological evidence that is required to establish spiroplasma serogroups (Whitcomb et al., 1987). In these criteria, it was recognized that reciprocal cross-reactivity was required to establish serogroups, as one-way crosses, which can be of considerable magnitude in some cases, are not unusual in mollicute serology. Every combination of Spiroplasma antigen/antibody reaction has been tested by DF and MI serology in the course of defining the 34 serogroups and 14 subgroups of spiroplasmas (Williamson et al., 1998). Every one of the $>5000$ reciprocal cross-reactions that are observed in these tests is consistent with the topologies in our phylogenetic reconstructions. Invariably, reciprocal serological cross-reactions are predictive of close phylogenetic affinity. Pairs of species that shared reciprocal serological cross-reactivities were invariably separated by very small evolutionary distances and were members of the same clade. For example, sequences that represented the seven sequenced subgroups of serogroup I (Citri clade) had sequence similarities of no less than $0 \cdot 986$. The three subgroups of the chrysopicola-syrphidicola-TAAS-1 clade (serogroup VIII) reported here, and an assemblage of other serogroup VIII strains that were not included in our reconstruction, had much higher similarity values $(>0.99)$ than serogroup I spiroplasmas, and all members of both serogroups I and VIII shared a high degree of intragroup serological reactivity (Williamson et al., 1998). When the $16 \mathrm{~S}$ rDNA similarity between species is $97 \%$ or more, Stackebrandt \& Goebel (1994) recommend that DNA-DNA reassociation studies should be performed to assist in the decision concerning possible species identity of the paired strains. In the case of spiroplasma subgroups, DNA-DNA reassociation studies have already been correlated with serological reactivities in species designations (Junca et al., 1980; Bové et al., 1983). Later, DNA-DNA reassociation studies were performed on the chrysopicola-syrphidicola-TAAS-1 clade (serogroup VIII; Gasparich et al., 1993) and the CB-1-Ar 1357 clade (serogroup XVI; Abalain-Colloc et al., 1993). Cross-reactions among strains in serogroups I, VIII and XVI represent the vast majority of spiroplasma intrasubgroup serological cross-reactivities. However, the sister species S. apis and $S$. montanense share a very low level of reciprocal crossreactivity (DF reciprocal cross-reactions of 20 or 40). No other reciprocal serological cross-reactivities were noted. Thus, results from Spiroplasma phylogeny and serology are congruent and serology - DF in particular - remains a practical means for identification of isolates from particular ecological situations.

It is important to point out that members of one subgroup may fail to cross-react serologically with one or more members of other subgroups. For example, subgroup VIII-2 does not cross-react with subgroup VIII-1, a circumstance that originally led to its being designated as a separate serogroup (Tully et al., 1987). However, both of these strains share numerous cross-reactions with other members of serogroup VIII. Strain BARC 2649 was also originally thought, on the basis of its failure to react with any of the designated subgroups, to represent a novel spiroplasma serogroup. However, its characteristically short, narrow helices, its ability to grow to very high titres in media and its aggressive utilization of arginine suggested that it might nevertheless belong to serogroup VIII. And indeed, 'bridge strains' - ones that cross-react with each of two noncross-reactive strains - were eventually found and strain BARC 2649 is now recognized - on the basis of its phenotypic properties and the close similarity of its $16 \mathrm{~S}$ rDNA sequence to those of other serogroup VIII spiroplasmas to represent an undescribed subgroup of serogroup VIII (Williamson et al., 1998).

Genome size. At one time, genome size - like sterol requirement - was considered to be a highly conserved trait among mollicutes and was therefore regarded as a useful character at higher levels of taxonomy (Freundt \& Razin, 1984). Earlier phylogenetic studies (Rogers et al., 1985; Weisburg et al., 1989; Maniloff, 1992) indicated that there had been several independent genome size reductions in mollicute evolution. The work of Pyle et al. (1988) and, later, of Neimark \& Lange (1990) and Carle et al. (1995), showed that mollicute genomes varied widely in size and could apparently change over short periods of evolutionary time. In the genus Spiroplasma, genomes vary widely in size, as they do in other mollicutes, and can even vary within species (Robertson et al., 1990). Genome-size change in S. citri has been observed in as few as 100 generations (Ye et al., 1995, 1996). As noted, the large size of $2220 \mathrm{kbp}$ for the S. ixodetis genome appears to represent a plesiomorphically large genome, from which size reductions may have occurred throughout the genus. Of course, we do not know the fraction of coding DNA in this species, so until the genome is sequenced, the question remains unanswered. In the large assemblage of spiroplasmas that exists in the arthropod/ leaf surface habitat (largely in the Apis clade sensu strictu), genome size appears to be in the range of about $1100-1500 \mathrm{kbp}$. Relatively low genome sizes in the mirum (1300 kbp) and chrysopicola-syrphidicola-TAAS-1 clades (1170-1270 kbp) may simply reflect a normal complement of potential coding regions without the surplus baggage from plasmid, virus and/or repeat sequences. In contrast, members of the Citri-Poulsonii clade (serogroups I and II) have genome sizes that range from 1460 to $2040 \mathrm{kbp}$. In some species, extreme genome-size reduction has occurred, particularly in the Apis clade. In this clade, there appear to be autapomorphic reductions for Spiroplasma sp. TIUS-1 (840 kbp), Spiroplasma monobiae (940 kbp), Spiroplasma sp. W115 (960 kbp), S. diminutum $(1080 \mathrm{kbp})$ and S. leptinotarsae (1085 kbp). As serogroup XXVIII (S. platyhelix) has not yet been sequenced, we cannot assess the phylogenetic significance of its genome size of $780 \mathrm{kbp}$, but it may represent yet another autapomorphic genome size reduction in Spiroplasma. Therefore, 
genome size reduction in mollicutes, which was once thought to be a rare event (Rogers et al., 1985), is, instead, frequent and distributed polyphyletically. In general, genome sizes in clades whose species have high similarity values (e.g. serogroup I, serogroup VIII and the apismontanense clade) tend to provide evidence for the use of genome size in spiroplasma classification. Whereas it was common for sister species and members of small clades to have very similar genome sizes, the total intrageneric range of genome sizes in Spiroplasma is $760-2220 \mathrm{kbp}$ (Carle et al., 1995).

$\mathbf{G}+\mathbf{C}$ content of spiroplasmal DNA. As with genome size, the degree to which $\mathrm{G}+\mathrm{C}$ content of chromosomal DNA is informative depends on the evolutionary distances between or among the species to be compared. In all spiroplasma serogroups in which constituent members have been divided into subgroups, DNA G $+\mathrm{C}$ content, like genome size, is an important clade property. In general, DNA $\mathrm{G}+\mathrm{C}$ content is more stable than genome size in this respect. For example, in the diminutum-CB-1-Ar 1357 clade, all three of the constituent members have DNA G + C contents of $26 \mathrm{~mol} \%$. In the chrysopicola-syrphidicolaTAAS-1 (serogroup VIII) clade, DNA G +C contents are $28-31 \mathrm{~mol} \%$. In the nine species or subgroups of serogroups I and II, the values are $26 \mathrm{~mol} \%$, with the exception of S. insolitum, which has a DNA G+C content of $28 \mathrm{~mol} \%$, an anomaly that led to the specific species epithet. Although the central tendency and the plesiomorphic state of DNA G $+\mathrm{C}$ content appear, on the basis of the DNA G $+\mathrm{C}$ content $(26 \mathrm{~mol} \%)$ of S. ixodetis, to be 25-27 mol\%, values higher than this might be considered to be apomorphic. In the apis-montanense clade, the DNA $\mathrm{G}+\mathrm{C}$ content is $28-30 \mathrm{~mol} \%$. In the TIUS-1 clade, the DNA G $+\mathrm{C}$ content is $28 \mathrm{~mol} \%$ and in Spiroplasma clarkii, there is an autapomorphic value of $29 \mathrm{~mol} \%$. Throughout the spiroplasmas and their non-helical descendants, there is a strong suggestion that close association with a host may be linked to lowering of the DNA G $+\mathrm{C}$ content. This is suggested strongly by the dramatic reduction in DNA $\mathrm{G}+\mathrm{C}$ content when the Entomoplasmataceae lineage diverged and one lineage became associated with ruminants. Finally, it is only fair, while advocating a role for DNA $\mathrm{G}+\mathrm{C}$ content in spiroplasma taxonomy, to acknowledge that there are sister species whose DNA G+C contents are rather discrepant. For example, strains W115 and BIUS- 1 have DNA G+C contents of 24 and $28 \mathrm{~mol} \%$, respectively; similarly, Spiroplasma velocicrescens and Spiroplasma chinense have values of 26 and $29 \mathrm{~mol} \%$, respectively. In summary, we believe that DNA G $+\mathrm{C}$ content, like genome size, provides valuable taxonomic information for species that are closely related. Of course, as the study of genomics proceeds, this information and DNADNA reassociation data will be replaced with wholegenome sequencing data (e.g. Persson, 2002).

Hosts. Many of the phenotypic and genotypic characteristics of the Citri-Poulsonii clade appear to be related directly to their close association with insect hosts and, in some cases, to the requirement for an obligate insect/plant phloem cycle. The tiny, arginine-consuming serogroup VIII spiroplasmas of the chrysopicola-syrphidicolaTAAS-1 clade coexist in their (largely) tabanid/plant surface cycles with a large assemblage of long spiroplasmas (members of the Apis clade sensu strictu), most of which do not catabolize arginine. These two types of tabanid spiroplasma appear to occupy different niches in their insect hosts. If this is true, requirements for optimization in these niches may have provided the selective forces that maintain these two very different phenotypic character suites. Also, as discussed in the following section, obligate affiliation with a particular host or biological cycle is usually associated with a decreased growth rate.

Sterol requirements. Unlike many other phenotypic and genotypic properties, sterol requirements in Entomoplasmatales and the ability to grow in $0.04 \%$ PES are distributed polyphyletically. Rose et al. (1993) showed that $S$. floricola grew in serum-free medium with and without PES. This supplement, which was used at the time in the context of sterol requirements, turned out to be inhibitory to some mollicutes, including four of eight acholeplasmas studied. In the Entomoplasmataceae, the genera Entomoplasma and Mesoplasma are polyphyletic, as discussed below. Thus, unlike other phenotypic and genotypic characters, phylogeny did not predict or explain sterol requirements or the ability to grow in sterol-free media in the presence of PES in the Entomoplasmataceae or, for that matter, in the Entomoplasmatales.

\section{Evolutionary considerations}

Spiroplasma evolution. Earlier phylogenetic analyses (Woese et al., 1980; Weisburg et al., 1989; Maniloff, 1992; Gundersen et al., 1994) and the cladograms herein indicate that the roots of Mollicutes lie in low-G + C, Grampositive bacteria, including certain clostridial lineages, and Erysipelothrix (Maidak et al., 2001). Evidence points strongly to polyphyly of Mollicutes in at least one respect: Asteroleplasma appears to be related more closely to certain Gram-positive bacteria than to any mollicute lineage. Monophyly of other mollicutes - specifically the Acholeplasma-Anaeroplasma-Phytoplasma and the Entomoplasmatales-PHUH clades - has not been established unequivocally. Woese et al. (1980) were non-committal on this point and little relevant supplemental information has been added since that time. Rather, the discovery of differential codon usage between the Acholeplasma-Anaeroplasma-Phytoplasma and Entomoplasmatales-PHUH clades (Renaudin et al., 1986) has re-emphasized the evolutionary gulf between the two clades. Noting the admonition of Siddall \& Whiting (1999) that hypotheses must be tested by additional data and not by other hypotheses, we believe that as large a sample as possible of Gram-positive bacteria must be assembled to provide an adequate test of this hypothesis. It is very easy for distantly related taxa to look 
like sisters if no intermediate taxa are available or, if available, are not included in the analysis. Although the two lineages may have been polyphyletic, extinction of walled relatives whose divergences were located between those of acholeplasmas and mycoplasmas may now obscure the real relationships between them.

It is clear that the plesiomorphic morphology of the mollicutes involved walled cells. Recent work on the cytoskeletal elements of Gram-positive bacteria, such as Bacillus (Jones et al., 2001), has given new insights into the evolution of Mollicutes. For example, Bacillus has a set of helical fibrils as part of its interior cytoskeletal structure (Jones et al., 2001). It is likely that the SpiroplasmaMycoplasma lineage possessed a substantial suite of cytoskeletal elements that conferred a (plesiomorphic) ability to form filaments, which may have been capable of some kind of movement. There appears to be continuity in the presence of actin throughout bacterial ancestral lineages (van den Ent et al., 2001) and this material has been deduced to be present in some spiroplasmas (Williamson et al., 1979b; Mouches et al., 1982; Simoneau \& Laberère, 1990). Some members of the Pneumoniae clade (e.g. M. iowae) have the capacity to form filaments in culture. To our knowledge, helicity has never been observed in the PHUH clade. However, it is possible that unknown ancestors of this lineage may have been helical, even after the Spiroplasma-Mycoplasma split. In Spiroplasma, helicity (albeit atypical) is present in the ixodetis clade and helicity, as a general property (Skripal, 1983), is synapomorphic for the genus. It is not known whether the unusual tightly coiled helicity of $S$. ixodetis cells is a plesiomorphic state, reflecting an early stage in the development of helices. However, Trachtenberg \& Gilad (2001) (S. Trachtenberg, personal communication) suggest that the major evolutionary step is the development of helicity itself and that variations, such as tightness of coiling, might be caused relatively easily without substantial genotypic change. As noted, the status of some hypothetically related, non-culturable organisms that are associated with various sex-ratio conditions in insects is unclear, as none of the organisms have in fact been envisioned. It is possible that other mollicutes of the spiroplasma lineage that are even more plesiomorphic than $S$. ixodetis may be discovered.

At least by the time of the divergence leading to the MirumCitri-Chrysopicola clade, helicity and motility, as they exist in a great majority of spiroplasmas species, had become firmly established. The only described species in the ixodetis clade is $S$. ixodetis and the large evolutionary distance between this organism and more apomorphic Spiroplasma species makes it difficult to determine evolutionary directionality of phenotypic and genotypic properties at the time of its divergence. Both the Citri-Poulsonii clade and the chrysopicola-syrphidicola-TAAS-1 clade have apomorphic traits. In serogroup I spiroplasmas, the large amounts of DNA that occur as repeat sequences and integrated viral and plasmid DNA apparently inflate the genome size greatly, without adding to the organism's coding capacity. If the basal position of the phloeminhabiting strain LB-12 in the Citri-Poulsonii clade reflects an ancestral habitat, the flower-surface habitat of S. insolitum (subgroup I-6) would represent an apomorphic return to the insect gut/flower surface habitat. The apomorphic nature of such a shift is in accord with the growth rate of S. insolitum, which is significantly slower than that of other plant surface-dwelling mollicutes. This species is not suited as well to existence on plant surfaces as those species in the Apis clade sensu strictu that appeared to have evolved and speciated in association with that strategy. The fact that the DNA G $+C$ content that accompanied this shift increased significantly is intriguing.

A more or less modal helical morphology was maintained in members of serogroups I and II, but was modified substantially in serogroup VIII by cell-size reduction, as described above. With morphological innovation in serogroup VIII came other modifications. The DNA G+C content of organisms in serogroup VIII is substantially higher than that of serogroup I organisms and the genome size is considerably smaller. Serogroup VIII appears to be radiating rapidly in dipterous insects - particularly horse flies - and is distributed worldwide. In contrast, members of the Citri-Poulsonii clade are associated with specific insect or insect/plant habitats.

Subsequent to the divergence that led to the CitriChrysopicola-Mirum clade, a major divergence occurred that led to the Apis clade sensu latu, which consists of the original Apis clade sensu strictu of Weisburg et al. (1989), but which now, as a result of the data herein, contains five novel species. These five species are, on the one hand, basal to the Apis clade sensu latu, and to the Entomoplasmataceae clade on the other. These basal members of the Apis clade sensu latu include Spiroplasma sp. TIUS-1, an organism with extremely poor helicity, S. alleghenense, another poorly helical organism, the uniquely funnel-shaped S. leptinotarsae and yet another organism with flawed helicity, S. lampyridicola, which is associated with firefly beetles. The fifth basal species is S. sabaudiense, the helical morphology of which is unremarkable.

The Apis clade sensu strictu contains many spiroplasmas that are acquired by their hosts from plant surfaces and then reside in the insect gut. At first inspection, the presence of this serogroup as a (sister) terminus in mollicute evolution is surprising, as Clark (1984) had proposed that the leaf surface/insect gut cycle is a primitive cycle from which other more complex maintenance cycles had evolved. Why, if we are to assume the existence of a modal tendency toward simple helicity and a simple insect gut/leaf surface existence, should the Apis clade sensu strictu be a terminus, rather than a basal clade? There is a simple hypothesis by which this conundrum can be explained. The hypothesis rests on the assumption, mentioned above, that host association confers a greater longevity on genotypes with close host associations than that experienced by genotypes in simple maintenance 
cycles. Once the accrual of large amounts of non-coding DNA in serogroup I and cell-size reduction in serogroup VIII are seen to be apomorphic, and once it is recognized that the tight cellular coiling of $S$. ixodetis could be a simple modification of basic helicity (and therefore also apomorphic), all apparent 'plesiomorphic' states, 'from which simple helices have been derived', vanish. There remains, then, only the simple helicity of $S$. mirum, whose morphology, DNA G $+\mathrm{C}$ content and genome size are very similar to those of the majority of members of the Apis clade sensu strictu.

There are several modifications within the Apis clade sensu strictu that indicate that evolutionary exploration continues in Spiroplasma. There is at least one specialist, S. clarkii, that is associated with a particular insect host (Cotinus nitida, the green june beetle). One of the clades in the Apis clade sensu latu, the BIUS-1-Floricola-Diabroticae-Monobiae clade, which was often, but not always, a feature of our trees, appears to be associated with insect/flower cycles, if we assume that fast-growing spiroplasma species isolated from insects that visit flowers regularly are in fact transmitted from insect to insect on flower surfaces. By the same token, spiroplasma species associated with tabanid flies - and presumptively passed (Wedincamp et al., 1996) horizontally from fly to fly, at least during the summer season, at common feeding sites [perhaps honeydew (Schutz \& Gaugler, 1989; Janzen \& Hunter, 1998)] - also cluster, but in different clades than those that contain flower-dwellers.

The question of whether spiroplasmas that are associated with tabanids are monophyletic remains unanswered. The phylogenetic reconstructions presented here do not resolve this question. In a dynamically evolving matrix of microorganisms that pass from plant surfaces to insect guts and vice versa, it would be expected that numerous exploratory host transfers would occur, most of which would fail. However, if one should succeed, there may be nothing to prevent that lineage from returning to its plesiomorphic host over a short period of time. Futuyma (1995) has discussed this type of reversion in terms of insect host specificities in plants. Suppose a 'monophyletic clade of tabanid specialists' transferred to another type of maintenance cycle over a brief period of evolutionary time. If there were a divergence that resulted in a secondary lineage that returned to the tabanid cycle, whether or not tabanid spiroplasmas were perceived to be monophyletic would depend on whether the intermediate lineage became extinct or, if it survived, whether it would be discovered. Since the genotypic extinction rates in Mollicutes (or any microbial taxon) are enormous, almost all 'monophyletic' groups must in reality be at least paraphyletic. Examined in this light, the question of monophyly of the tabanid spiroplasmas is seen to be (i) indeterminable and (ii) effectively irrelevant.

Spiroplasmas that are associated with mosquitoes occur in several clades within the Apis clade sensu latu. Some are associated with spiroplasmas that are transmitted on flower surfaces. This is not surprising, as a study of mosquito spiroplasmas (Chastel \& Humphery-Smith, 1991) assumed that these organisms are transmitted from mosquito to mosquito when the insects feed on flower surfaces. It is remarkable that no tabanid spiroplasma has ever been isolated from a mosquito, or vice versa. It is also remarkable that the tabanid spiroplasma clades do not contain any mosquito spiroplasmas. The small clade that consists of the sister species $S$. apis and $S$. montanense is distinguishable from other clades of the Apis clade sensu strictu in several respects. S. apis has been recovered from tabanids, honeybees and a number of insect species, and from flower surfaces. Thus it is more of a generalist than other spiroplasmas that are isolated from tabanids. S. montanense occurs in the northern United States and Canada and is often isolated from Hybomitra horse flies. Recent attention has been focused on the biogeography of micro-organisms (Staley \& Gosink, 1999). Thus, it is of interest to note that this species is one of several tabanid spiroplasmas that appear to have a clear biogeography (Whitcomb et al., 1990).

\section{Scenario for divergence of the mycoides group from} Spiroplasma. In general, the older a lineage, the more opportunity it has had to radiate into other hosts and/or habitats. Mycoplasmas of the PHUH clade are found in many vertebrate and invertebrate animals, including tortoises (Brown et al., 1995), alligators (Brown et al., 2001), seals (Heldtander Königsson, 2001) and crocodiles (Kirchhoff et al., 1997), as well as primates [including man (Somerson \& Cole, 1979)] and the usual ruminant animals. As the search among non-vertebrate hosts has been peremptory at best, it is reasonable to presume that Mycoplasma species of the Hominis and Pneumoniae clades are spread widely throughout the animal kingdom. In contrast, the M. mycoides clade occurs only in ruminants and the evolutionary distances among the species are small. All trees, including those developed in the sophisticated analyses of K.-E. Johansson's group [reviewed by Johansson \& Pettersson (2002)] suggest that entomoplasmas (and/or mesoplasmas) arose first and that the Mycoides clade arose from an entomoplasmal ancestor. When this is considered, studies that suggest a possible interaction with fleas of bovine animals (DaMassa et al., 1994) can be seen in a new light. Ruminants first arose, according to fossil evidence, only in the mid-Eocene, perhaps 40 million years ago. If the Mycoides clade has radiated only in ruminants, it must therefore be a taxon that has evolved relatively recently. On the other hand, Mycoplasma species of the Hominis and Pneumoniae clades may have arisen several hundred million years ago.

Just as the Mycoides clade arose from an ancestral root in the Entomoplasmataceae, so species of the Entomoplasmataceae themselves appear to have arisen from ancestors that are shared with the Apis clade sensu latu. In the basal divergences of the Apis clade sensu latu, two clades of spiroplasmas - the lampyridicola-leptinotarsae clade and the alleghenense-sabaudiense-TIUS-1 clade - show 
especially labile morphology. This contrasts with the more stable morphology in members of the Apis clade sensu strictu, whose cells generally retain helicity and motility throughout cultural manipulations. In particular, serogroup XXVIII strain TIUS-1, whilst exhibiting occasional helical forms, is seen mostly in culture as a non-helical mollicute one that, without an isolation history that includes extensive microscopic observations, could easily be mistaken for a member of the Entomoplasmaceae. The deterioration of helicity in species such as TIUS-1, which are related more closely to the Mycoides-Entomoplasmataceae clade than most other spiroplasmas, suggests a scenario for the evolution of this clade of non-helical entomoplasmas. Thus, the concept of a relatively recent origin of the Mycoides clade from an entomoplasmal ancestor is entirely consistent with existing data and evolutionary constraints.

\section{Phylogenetic and Linnaean classification of Mollicutes}

Phylogenetic versus Linnaean classifications. The phylogenetic classification outlined, in which nested sets (clades) of organisms that are likely to have had common ancestors are identified, contrasts sharply with conventional Linnaean classifications, in which species, genera, families and orders are delineated. In these classifications, whatever the clade structure of the dataset, existing biodiversity is made to fit into a predetermined template with a fixed number of hierarchical levels. The advantage of this kind of classification is its sharp, although possibly artificial, boundaries. When organisms are of practical importance (as M. mycoides certainly is), the binomial system offers a means for establishment of identification and quarantine procedures and the scientific community outside the walls of systematics laboratories is generally able to count on the classification being relatively stable.

On the other hand, phylogenetic classifications are unconstrained by templates. Given the discrepancy in taxic numbers and/or sampling among clades in many phylogenetic reconstructions, it may be awkward to shoehorn the data into a Linnaean structure. Also, even if the dataset of taxa and characters remains stable, phylogenetic classifications may change, depending on the outcome of arguments among systematists. Furthermore, in the era of molecular systematics, as new technologies are introduced and new characters become available, it is inevitable, no matter what technique is replacing what, that the new phylogenetic classification based on an enlarged set of characters will differ from the previous versions and if new taxa are added, the fundamental clade structure will be altered. For example, species that are perceived at first to be sister species may turn out to be separated by a considerable evolutionary distance, in comparison to newly discovered species that are related more closely to either one of them.

When changes in phylogenetic reconstructions occur, it is very common for molecular systematists to demand immediately that binomial nomenclature should be revised to accommodate the latest phylogenetic groupings. It is insufficiently appreciated that all phylogenetic analyses are only hypotheses and should be tested before they can be implemented properly. Kluge (1997) argues forcefully that the best test of a hypothesis is to make every attempt to falsify it, rather than to verify it. What is the best way to test a hypothesis in microbial taxonomy? Eukaryote systematists, often stuck with a dataset that is difficult or impossible to enlarge, tend to become embroiled in controversy over which algorithms should be used for analysis of the same dataset. Microbiologists, who have much less trouble expanding the scope of their taxic sampling, are more apt to be attracted to the admonition of Siddall \& Whiting (1999) that - as noted earlier - hypotheses cannot be tested by formulating hypotheses and that they can be tested only by additional data (specifically, more characters and/or more taxa).

Phylogenetic classification of Entomoplasmatales and Linnaean taxonomy of the genus Mycoplasma. In the case of Mollicutes, the initial deep-branching patterns observed by Woese et al. (1980), Weisburg et al. (1989), Maniloff (1992), Johansson \& Pettersson (2002; many trees summarized), Maidak et al. (2001) and in this paper are mutually supportive. With two exceptions, species in Entomoplasmatales and the genus Mycoplasma are classified in Linnaean nomenclature in a way that is consistent with phylogeny.

The Mesoplasma problem. The simplest anomaly (from the standpoint of available resolution) in present Mollicutes classification is that phylogenetic classifications show that the genera Entomoplasma and Mesoplasma are polyphyletic. Actually, at the time of the designation of Entomoplasmataceae, the authors were aware that the trees of Weisburg et al. (1989) showed that Mesoplasma and Entomoplasma might be related rather closely. It was, nonetheless, logical for both genera to be proposed. To understand why both these genera were designated, it is important to realize that the results of Weisburg et al. (1989) were based on distance analyses, which have been criticized by many systematists. At that time, neighbourjoining (Saitou \& Nei, 1987) was beginning to be employed by microbiologists, but it was only recently that maximum-likelihood (Felsenstein, 1981; Saitou \& Imanishi, 1989) and maximum-parsimony (Swofford, 1983; Gundersen et al., 1994) have begun to see widespread use in microbial taxonomy. On these grounds alone, it would have been - retrospectively - premature to have placed all the entomoplasmas and mesoplasmas into a single genus. In 1993, it seemed to be a giant step to remove the species that are now considered to be mesoplasmas from Acholeplasma, and species that are now considered to be entomoplasmas from Mycoplasma, where they had been respectively placed. To have taken not only this large a step, but, in addition, to have combined the 
two taxa into a single novel genus on the basis of limited phylogenetic information, was contraindicated.

A second and even more important factor was involved in the decision to propose two genera within the Entomoplasmataceae. It has only been in the past decade that it became clear that sterol requirement (or non-requirement) is not a profound and significant character at higher taxonomic levels, as had been thought, but is instead a character that may vary among species in a single genus. It was the extensive studies of Rose et al. (1993), performed soon after the 1993 revision of Mollicutes, that revealed the difficulties with taxonomic tests concerning the sterol requirement in Mollicutes. These authors found that the genus Spiroplasma contained both sterol-requiring and -non-requiring species. Also, although Rose et al. (1993) studied the ability of mollicutes to grow in PESsupplemented medium, a definitive tie to sterol metabolism could not be demonstrated. This continues to be the case, so the basis for the test remains uncertain.

Today, with accumulated evidence from many different methods of phylogenetic analysis and with additional sequences now available, the original suggestion of polyphyly has been confirmed repeatedly. It now seems anomalous to retain both genera and, indeed, there have already been calls for them to be combined into a single genus - presumably Entomoplasma (Johansson \& Pettersson, 2002).

Polyphyly of Mycoplasma. There is no 'quick fix' for the second anomaly in the classification of Mollicutes. It is now clear that the type species of the genus Mycoplasma and a small group of related mycoplasmal inhabitants of ruminants are derived not from an ancestor that is shared with the $>100$ Mycoplasma species of the Hominis and Pneumoniae clades, but instead from an ancestor in the Entomoplasmataceae. Species of Entomoplasmataceae, in turn, have an ancestral root in the genus Spiroplasma. Thus, the genus Mycoplasma, as currently defined (Freundt \& Razin, 1984), is polyphyletic.

If the mycoplasmas were simply environmental isolates with no practical baggage, the problem could be remedied easily; the genus name would be retained for M. mycoides and its allies and a novel genus name would be proposed for the remaining mycoplasmas. However, species of the PHUH clade are associated with $>50$ disease conditions (Freundt \& Razin, 1984; J. G. Tully, personal communication) and thousands of papers have been published under the existing names. If one were to change the genus name of one of the two Mycoplasma clades, it would be easier to change the genus name of members of the Mycoides clade (Johansson \& Pettersson, 2002). However, not only are these organisms, like members of the PHUH clade, associated with a very large body of literature, but the name M. mycoides is associated with practical identifications and quarantines of important disease agents. More importantly, M. mycoides is the type species of Mycoplasma,
Mycoplasmataceae and Mycoplasmatales, so any name-change would have to be approved by the Judicial Commission.

It is our view that, in the case of the polyphyly of the genus Mycoplasma, it is sensible for the phylogenetic and Linnaean characterization to disagree on matters that concern genus names for members of the two clades of Mycoplasma species. It seems pointless to perform, at great expense to veterinary science and mycoplasmology, a minor fix on a Linnaean classification that contains myriads of other major discrepancies between Linnaean and phylogenetic classifications.

\section{ACKNOWLEDGEMENTS}

The authors acknowledge the assistance, advice and decades of counsel provided by J. G. Tully. We also thank Tom Knight, Nicole Ellis, Doug Bost and P. C. Collins for their assistance in sequence determination and Mark Siddall, Ulrich Melcher, Tom Knight, Jacque Fletcher, Eric Brown, Mark Allard and Karl-Erik Johansson for useful comments on the manuscript.

\section{REFERENCES}

Abalain-Colloc, M. L., Williamson, D. L., Carle, P. \& 7 other authors (1993). Division of group XVI spiroplasmas into subgroups. Int J Syst Bacteriol 43, 342-346.

Bové, J. M., Mouches, C., Carle-Junca, P., Degorce-Dumas, J. R., Tully, J. G. \& Whitcomb, R. F. (1983). Spiroplasmas of group I: the Spiroplasma citri cluster. Yale J Biol Med 56, 573-582.

Bové, J. M., Tully, J. G., Madof, S., Meymerit, J.-C., Blanchard, A., Chastel, C. \& Kobisch, M. (1994). Exhibit on History of Mycoplasmology and the IOM (Special Publication of the IOM). Bordeaux, France: International Organization for Mycoplasmology.

Brown, D. R., Crenshaw, B. C., McLaughlin, G. S., Schumacher, I. M., McKenna, C. E., Klein, P. A., Jacobson, E. R. \& Brown, M. B. (1995). Taxonomic analysis of the tortoise mycoplasmas Mycoplasma agassizii and Mycoplasma testudinis by 16S rRNA gene sequence comparison. Int J Syst Bacteriol 45, 348-350.

Brown, D. R., Farley, J. M., Zacher, L. A., Carlton, J. M.-R., Clippinger, T. L., Tully, J. G. \& Brown, M. B. (2001). Mycoplasma alligatoris sp. nov., from American alligators. Int $J$ Syst Evol Microbiol 51, 419-424.

Burgdorfer, W., Brinton, L. P. \& Hughes, L. E. (1975). Isolation and characterization of symbiotes from the Rocky Mountain wood tick, Dermacentor andersoni. J Invertebr Pathol 22, 424-434.

Calavan, E. C. \& Bové, J. M. (1989). Ecology of Spiroplasma citri. In The Mycoplasmas, pp. 425-485. Edited by R. F. Whitcomb \& J. G. Tully. San Diego, CA: Academic Press.

Carle, P., Laigret, F., Tully, J. G. \& Bové, J. M. (1995). Heterogeneity of genome sizes within the genus Spiroplasma. Int J Syst Bacteriol 45, 178-181.

Carmean, D. \& Crespi, B. J. (1995). Do long branches attract flies? Nature 373, 666.

Carpenter, J. M. (1996). Uninformative bootstrapping. Cladistics 12, 177-181.

Chastel, C. \& Humphery-Smith, I. (1991). Mosquito spiroplasmas. Adv Dis Vector Res 7, 149-205.

Clark, T. B. (1977). Spiroplasma sp., a new pathogen in honey bees. J Invertebr Pathol 29, 112-113. 
Clark, T. B. (1982). Spiroplasmas: diversity of arthropod reservoirs and host-parasite relationships. Science 212, 57-59.

Clark, T. B. (1984). Diversity of spiroplasma host-parasite relationships. Isr J Med Sci 20, 995-997.

Clark, T. B., Tully, J. G., Rose, D. L., Henegar, R. \& Whitcomb, R. F. (1986). Acholeplasmas and similar nonsterol-requiring mollicutes from insects: missing link in microbial ecology. Curr Microbiol 13, $11-16$.

Clark, T. B., Henegar, R. B., Rosen, L. \& 7 other authors (1987). New spiroplasmas from insects and flowers: isolation, ecology, and host association. Isr J Med Sci 23, 687-690.

DaMassa, A. J., Tully, J. G., Rose, D. L., Pitcher, D., Leach, R. H. \& Cottew, G. S. (1994). Mycoplasma auris sp. nov., Mycoplasma cottewii sp. nov., and Mycoplasma yeatsii sp. nov., new sterolrequiring mollicutes from the external ear canals of goats. Int J Syst Bacteriol 44, 479-484.

Davis, R. E. (1978). Spiroplasma associated with flowers of the tulip tree (Liriodendron tulipifera L.). Can J Microbiol 24, 954-959.

Davis, R. E., Worley, J. F., Whitcomb, R. F., Ishijima, T. \& Steere, R. L. (1972). Helical filaments produced by a mycoplasma-like organism associated with corn stunt disease. Science 176, 521-523.

Dodge, D. E., Ellis, N. E., Collins, P. C., Bost, D. A., Gasparich, G., Williamson, D. L., Tully, J. G. \& Whitcomb, R. F. (1998). Taxonomic classification of members of the genus Spiroplasma by fluorescent DNA sequencing of the $16 \mathrm{~S}$ rRNA gene. In Abstracts of the Congress of the International Organization for Mycoplasmology, Canberra, Australia, July 1998.

Edward, D. G. ff. \& Freundt, E. A. (1956). The classification and nomenclature of organisms of the pleuropneumonia group. J Gen Microbiol 14, 197-207.

FAO EMPRES (2000). Recognising CBPP: a Field Manual for Recognition. Rome: FAO EMPRES.

Farris, J. S., Albert, V. A., Källersjö, M., Lipscomb, D. \& Kluge, A. G. (1999). Parsimony jackknifing outperforms neighbor-joining. Cladistics 12, 99-124.

Felsenstein, J. (1981). Evolutionary trees from DNA sequences: a maximum likelihood approach. J Mol Evol 17, 368-376.

Freundt, E. A. \& Razin, S. (1984). Genus I. Mycoplasma. In Bergey's Manual of Systematic Bacteriology, vol. 1, pp. 742-770. Edited by N. R. Krieg \& J. G. Holt. Baltimore, MD: Williams \& Wilkins.

Fukatsu, T. \& Nikoh, N. (2000). Endosymbiotic microbiota of the bamboo pseudococcid Antonina crawii (Insecta, Homoptera). Appl Environ Microbiol 66, 643-650.

Fukatsu, T., Tsuchida, T., Nikoh, N. \& Koga, R. (2001). Spiroplasma symbiont of the pea aphid, Acyrthosiphon pisum (Insecta: Homoptera). Appl Environ Microbiol 67, 1284-1291.

Futuyma, D. J. (1995). The uses of evolutionary biology. Science 267, 41-42.

Garnier, M., Clerc, M. \& Bové, J. M. (1984). Growth and division of Spiroplasma citri: elongation of elementary helices. J Bacteriol 158, 23-28.

Gasparich, G. E., Saillard, C., Clark, E. A., Konai, M., French, F. E., Tully, J. G., Hackett, K. J. \& Whitcomb, R. F. (1993). Serologic and genomic relatedness of group VIII and group XVII spiroplasmas and subdivision of spiroplasma group VIII into subgroups. Int J Syst Bacteriol 43, 338-341.

Gasparich, G. E., Hackett, K. J., French, F. E. \& Whitcomb, R. F. (1998). Serologic and genomic relatedness of group XIV spiroplasma isolates from a lampyrid beetle and tabanid flies: an ecologic paradox. Int J Syst Bacteriol 48, 321-324.
Gundersen, D. E., Lee, I.-M., Rehner, S. A., Davis, R. E. \& Kingsbury, D. T. (1994). Phylogeny of mycoplasmalike organisms (phytoplasmas): a basis for their classification. J Bacteriol 176, 5244-5254.

Hackett, K. J. (1990). Adaptational biology and spiroplasmas. Zentbl Bakteriol Suppl 20, 21-32.

Hackett, K. J. \& Clark, T. B. (1989). The ecology of spiroplasmas. In The Mycoplasmas, vol. 5, pp. 113-200. Edited by R. F. Whitcomb \& J. G. Tully. New York: Academic Press.

Hackett, K., Clark, T. B., Hicks, A., Whitcomb, R. F., Lowry, E. \& Batra, S. W. T. (1984). Occurrence and frequency of subgroup I-6 spiroplasma in arthropods associated with old fields in Maryland and Virginia. Isr J Med Sci 20, 1006-1008.

Hackett, K. J., Whitcomb, R. F., Henegar, R. B., Wagner, A. C., Clark, E. A., Tully, J. G., Molina, F., McKay, W. \& Santini, P. (1990). Mollicute diversity in arthropod hosts. Zentbl Bakteriol Suppl 20, 441-454.

Hackett, K. J., Whitcomb, R. F., Tully, J. G. \& 7 other authors (1992). Lampyridae (Coleoptera): a plethora of mollicute associations. Microb Ecol 23, 181-193.

Hackett, K. J., Whitcomb, R. F., Clark, T. B. \& 12 other authors (1996a). Spiroplasma leptinotarsae sp. nov., a mollicute uniquely adapted to its host, the Colorado potato beetle, Leptinotarsa decemlineata (Coleoptera: Chrysomelidae). Int J Syst Bacteriol 46, 906-911.

Hackett, K. J., Whitcomb, R. F., French, F. E. \& 10 other authors (1996b). Spiroplasma corruscae sp. nov., from a firefly beetle (Coleoptera: Lampyridae) and tabanid flies (Diptera: Tabanidae). Int J Syst Bacteriol 46, 947-950.

Hansmann, S. \& Martin, W. (2000). Phylogeny of 33 ribosomal and six other proteins encoded in an ancient gene cluster that is conserved across prokaryotic genomes: influence of excluding poorly alignable sites from analysis. Int J Syst Evol Microbiol 50, 1655-1663.

Heldtander, M., Pettersson, B., Tully, J. G. \& Johansson, K.-E. (1998). Sequences of the 16S rRNA genes and phylogeny of the goat mycoplasmas Mycoplasma adleri, Mycoplasma auris, Mycoplasma cottewii and Mycoplasma yeatsii. Int J Syst Bacteriol 48, 263-268.

Heldtander Königsson, M. (2001). Phylogeny, diversity, detection: multiple uses of $16 S \mathrm{rRNA}$ genes in veterinary bacteriology. $\mathrm{PhD}$ thesis, Swedish University of Agricultural Sciences, Uppsala, Sweden.

Hurst, G. D. D. \& Jiggins, F. M. (2000). Male-killing bacteria in insects: mechanisms, incidence, and implications. Emerg Infect Dis 6, 329-336.

Hurst, G. G. D., Graf von der Schulenburg, J. H., Majerus, T. M. O., Bertrand, D., Zakharov, I. A., Baungaard, J., Völkl, W., Stouthamer, R. \& Majerus, M. E. N. (1999). Invasion of one insect species, Adalia bipunctata, by two different male-killing bacteria. Insect Mol Biol 8, 133-139.

International Committee on Systematic Bacteriology Subcommittee on the Taxonomy of Mollicutes (1995). Revised minimal standards for descriptions of new species of the class Mollicutes (Division Tenericutes). Int J Syst Bacteriol 45, 605-612.

Janzen, T. A. \& Hunter, F. F. (1998). Honeydew sugars in wild-caught female deer flies (Diptera: Tabanidae). J Med Entomol 35, 685-689. Jiggins, F. M., Hurst, G. D. D., Jiggins, C. D., von der Schulenburg, J. H. G. \& Majerus, M. E. N. (2000). The butterfly Danaus chrysippus is infected by a male-killing Spiroplasma bacterium. Parasitology 120, 439-446.

Johansson, K.-E. \& Pettersson, B. (2002). Taxonomy of Mollicutes. In Molecular Biology and Pathogenicity of Mycoplasmas, pp. 1-29. Edited by S. Razin \& R. Herrmann. London: Kluwer. 
Jones, L. J. F., Carballido-López, R. \& Errington, J. (2001). Control of cell shape in bacteria: helical, actin-like filaments in Bacillus subtilis. Cell 104, 913-922.

Junca, P., Saillard, C., Tully, J. G. \& 10 other authors (1980). Caractérisation de spiroplasmes isolés d'insectes et de fleurs de France continentale, de Corse et du Maroc. Proposition pour une classification des spiroplasmes. $C R$ Seances Acad Sci D 290, 1209-1212 (in French).

Kirchhoff, H., Mohan, K., Schmidt, R. \& 7 other authors (1997). Mycoplasma crocodyli sp. nov., a new species from crocodiles. Int J Syst Bacteriol 47, 742-746.

Kluge, A. G. (1997). Testability and the refutation and corroboration of cladistic hypotheses. Cladistics 13, 81-96.

Konai, M., Clark, E. A., Camp, M., Koeh, A. L. \& Whitcomb, R. F. (1996). Temperature ranges, growth optima, and growth rates of Spiroplasma (Spiroplasmataceae, class Mollicutes) species. Curr Microbiol 32, 314-319.

Koski, L. B. \& Golding, G. B. (2001). The closest BLAST hit is often not the nearest neighbor. J Mol Evol 52, 540-542.

Le Goff, F., Humphery-Smith, I., Leclercq, M. \& Chastel, C. (1991). Spiroplasmas from European Tabanidae. Med Vet Entomol 5, 143-144.

Lei, J. D., Su, H. J. \& Chen, T. A. (1979). Spiroplasmas isolated from the green leafbug, Trigonotylus ruficornis Geoffrey. In Proceedings of the US-ROC Plant Mycoplasma Seminar, pp. 89-97. Taipei, Taiwan: National Science Council.

Ludwig, W. \& Schleifer, K. H. (1994). Bacterial phylogeny based on $16 \mathrm{~S}$ and $23 \mathrm{~S}$ rRNA sequence analysis. FEMS Microbiol Rev 15, 155-173.

Ludwig, W. \& Schleifer, K.-H. (1999). Phylogeny of bacteria beyond the $16 \mathrm{~S}$ rRNA standard. ASM News 65, 752-757.

Maddison, W. P. \& Maddison, D. R. (1992). MacClade: analysis of phylogeny and character evolution, version 3.0. Sunderland, MA: Sinauer Associates.

Maidak, B. L., Cole, J. R., Lilburn, T. G. \& 7 other authors (2001). The RDP-II (Ribosomal Database Project). Nucleic Acids Res 29, 173-174.

Maniloff, J. (1992). Phylogeny of mycoplasmas. In Mycoplasmas: Molecular Biology and Pathogenesis, pp. 549-559. Edited by J. Maniloff, R. N. McElhaney, L. R. Finch \& J. B. Baseman. Washington, DC: American Society of Microbiololgy.

Maniloff, J. (2002). Phylogeny and evolution. In Molecular Biology and Pathogenicity of Mycoplasmas, pp. 31-43. Edited by S. Razin \& R. Herrmann. London: Kluwer.

McCoy, R. E., Williams, D. S. \& Thomas, D. L. (1979). Isolation of mycoplasmas from flowers. In Proceedings of the US-ROC Plant Mycoplasma Seminar, pp. 75-81. Taipei, Taiwan: National Science Council.

Mouches, C., Menara, A., Geny, B., Charlemagne, D. \& Bové, J. M. (1982). Synthesis of Spiroplasma citri protein specifically recognized by rabbit immunoglobulin to rabbit actin. Rev Infect Dis 4, 5277.

Murray, R. G. E. \& Stackebrandt, E. (1995). Taxonomic note: implementation of the provisional status Candidatus for incompletely described procaryotes. Int J Syst Bacteriol 45, 186-187.

Neimark, H. C. \& Lange, C. S. (1990). Pulsed-field electrophoresis indicates full-length mycoplasma chromosomes range widely in size. Nucleic Acids Res 18, 5443-5448.

Neimark, H. \& Kocan, K. M. (1997). The cell wall-less rickettsia Eperythrozoon wenyonii is a Mycoplasma. FEMS Microbiol Lett 156, 287-291.

Neimark, H., Johansson, K.-E., Rikihisa, Y. \& Tully, J. G. (2001). Proposal to transfer some members of the genera Haemobartonella and Eperythrozoon to the genus Mycoplasma with descriptions of 'Candidatus Mycoplasma haemofelis', 'Candidatus Mycoplasma haemomuris', 'Candidatus Mycoplasma haemosuis' and 'Candidatus Mycoplasma wenyoni'. Int J Syst Evol Microbiol 51, 891-899.

Nowak, J. (1929). Morphologie, nature et cycle évolutif du microbe de la péripneumoniae des bovidés. Ann Inst Pasteur (Paris) 43, 13301352 (in French).

Persson, A. M. (2002). Molecular characterization of Mycoplasma mycoides subsp. mycoides SC. PhD thesis, Swedish University of Agricultural Sciences, Uppsala, Sweden.

Poulson, D. F. \& Sakaguchi, B. (1961). Nature of the "sex-ratio" agent in Drosophila. Science 133, 1489-1490.

Provost, A., Perreau, P., Beard, A., Le Goff, C., Martel, J. L. \& Cottew, G. S. (1987). Contagious bovine pleuropneumonia. In Revue Scientifique et Technique, pp. 625-679. Paris: Office International des Epizooties (in French).

Pyle, L. E., Corcoran, L. E., Cocks, B. G., Bergemann, A. D., Whitley, J. C. \& Finch, L. R. (1988). Pulsed-field electrophoresis indicates larger-than-expected sizes for mycoplasma genomes. Nucleic Acids Res 16, 6015-6025.

Renaudin, J., Pascarel, M.-C., Saillard, C., Chevalier, C. \& Bové, J. M. (1986). Chez les spiroplasmes le codon UGA n'est pas non sens et semble coder pour le tryptophane. C R Acad Sci Paris Ser III 303, 539-540 (in French).

Robertson, J. A., Pyle, L. E., Stemke, G. W. \& Finch, L. R. (1990). Human ureaplasmas show diverse genome sizes by pulsed-field electrophoresis. Nucleic Acids Res 18, 1451-1455.

Rogers, M. J., Simmons, J., Walker, R. T. \& 8 other authors (1985). Construction of the mycoplasma evolutionary tree from $5 \mathrm{~S}$ rRNA sequence data. Proc Natl Acad Sci U S A 82, 1160-1164.

Rose, D. L., Tully, J. G., Bové, J. M. \& Whitcomb, R. F. (1993). A test for measuring growth responses of mollicutes to serum and polyoxyethylene sorbitan. Int J Syst Bacteriol 43, 527-532.

Saglio, P., Lhospital, M., Laflèche, D., Dupont, G., Bové, J. M., Tully, J. G. \& Freundt, E. A. (1973). Spiroplasma citri gen. and sp. n.: a mycoplasma-like organism associated with "stubborn" disease of citrus. Int J Syst Bacteriol 23, 191-204.

Saitou, N. \& Nei, M. (1987). The neighbor-joining method: a new method for reconstructing phylogenetic trees. Mol Biol Evol 4, 406-425.

Saitou, N. \& Imanishi, T. (1989). Relative efficiencies of the FitchMargoliash, maximum-parsimony, maximum-likelihood, minimumevolution, and neighbor-joining methods of phylogenetic tree construction in obtaining the correct tree. Mol Biol Evol 6, 514-525.

Schutz, S. J. \& Gaugler, R. (1989). Honeydew-feeding behavior of salt marsh horse flies (Diptera: Tabanidae). J Med Entomol 26, 471-473.

Siddall, M. E. \& Whiting, M. F. (1999). Long-branch abstractions. Cladistics 15, 9-24.

Simoneau, P. \& Laberère, J. (1990). Immunochemical identification of an actin-like protein from Spiroplasma citri. Z Bakteriol (Suppl) 20, 926-931.

Skripal, I. G. (1983). Revival of the name Spiroplasmataceae fam. nov., nom. rev., omitted from the 1980 Approved Lists of Bacterial Names. Int J Syst Bacteriol 33, 408.

Sokolova, M. I., Zinkevich, N. S. \& Zakharov, I. A. (2002). Bacteria in ovarioles of females from maleless families of ladybird beetles Adalia bipunctata L. (Coleoptera: Coccinellidae) naturally infected with Rickettsia, Wolbachia, and Spiroplasma. J Invertebr Pathol 79, 72-79.

Somerson, N. L. \& Cole, B. C. (1979). The mycoplasma flora of human and nonhuman primates. In The Mycoplasmas, vol. 2, 
pp. 191-216. Edited by J. G. Tully \& R. F. Whitcomb. New York: Academic Press.

Stackebrandt, E. \& Goebel, B. M. (1994). Taxonomic note: a place for DNA-DNA reassociation and 16S rRNA sequence analysis in the present species definition in bacteriology. Int J Syst Bacteriol 44, 846-849.

Staley, J. T. \& Gosink, J. J. (1999). Poles apart: biodiversity and biogeography of polar sea ice bacteria. Annu Rev Microbiol 53, 189-215.

Stevens, C., Tang, A. Y., Jenkins, E. \& 12 other authors (1997). Spiroplasma lampyridicola sp. nov., from the firefly beetle Photuris pennsylvanicus. Int J Syst Bacteriol 47, 709-712.

Stewart, K. M. (2001). Group VIII spiroplasmas of Costa Rica. MS thesis, Georgia Southern University, Statesboro, GA, USA.

Stiller, J. W. \& Hall, B. D. (1999). Long-branch attraction and the rDNA model of early eukaryotic evolution. Mol Biol Evol 16, 1270-1279.

Swofford, D. (1983). PAUP: Phylogenetic Analysis Using Parsimony, version 3.1. Illinois Natural History Survey, Champaign.

Swofford, D. L. (1998). PAUP*: Phylogenetic Analysis Using Parsimony ( ${ }^{*}$ and other methods) Version 4. Sinauer Associates, Sunderland, MA.

Thompson, J. D., Higgins, D. G. \& Gibson, T. J. (1994). CLUSTAL W: improving the sensitivity of progressive multiple sequence alignment through sequence weighting, position-specific gap penalties and weight matrix choice. Nucleic Acids Res 22, 4673-4680.

Trachtenberg, S. \& Gilad, R. (2001). A bacterial linear motor: cellular and molecular organization of the contractile cytoskeleton of the helical bacterium Spiroplasma melliferum BC3. Mol Microbiol 41, 827-848.

Tully, J. G. \& Whitcomb, R. F. (1990). The genus Spiroplasma. In The Prokaryotes, pp. 1960-1980. Edited by M. P. Starr, H. Stolp, H. G. Trüper, A. Balows \& H. G. Schlegel. New York: Springer.

Tully, J. G., Whitcomb, R. F., Williamson, D. L. \& Clark, H. F. (1976). Suckling mouse cataract agent is a helical wall-free prokaryote (spiroplasma) pathogenic for vertebrates. Nature 259, 117-120.

Tully, J. G., Whitcomb, R. F., Clark, H. F. \& Williamson, D. L. (1977). Pathogenic mycoplasmas: cultivation and vertebrate pathogenicity of a new spiroplasma. Science 195, 892-894.

Tully, J. G., Whitcomb, R. F., Rose, D. L. \& Bové, J. M. (1982). Spiroplasma mirum, a new species from the rabbit tick (Haemaphysalis leporispalustris). Int J Syst Bacteriol 32, 92-100.

Tully, J. G., Rose, D. L., Clark, E., Carle, P., Bové, J. M., Henegar, R. B., Whitcomb, R. F., Colflesh, D. E. \& Williamson, D. L. (1987). Revised group classification of the genus Spiroplasma (class Mollicutes), with proposed new groups XII to XXIII. Int $J$ Syst Bacteriol 37, 357-364.

Tully, J. G., Bové, J. M., Laigret, F. \& Whitcomb, R. F. (1993). Revised taxonomy of the class Mollicutes: proposed elevation of a monophyletic cluster of arthropod-associated mollicutes to ordinal rank (Entomoplasmatales ord. nov.), with provision for familial rank to separate species with nonhelical morphology (Entomoplasmataceae ord. nov.) from helical species (Spiroplasmataceae), and emended descriptions of the order Mycoplasmatales, family Mycoplasmataceae. Int J Syst Bacteriol 43, 378-385.

Tully, J. G., Whitcomb, R. F., Hackett, K. J., Rose, D. L., Henegar, R. B., Bové, J. M., Carle, P., Williamson, D. L. \& Clark, T. B. (1994). Taxonomic descriptions of eight new non-sterol-requiring mollicutes assigned to the genus Mesoplasma. Int J Syst Bacteriol 44, 685-693.

Tully, J. G., Rose, D. L., Yunker, C. E., Carle, P., Bové, J. M., Williamson, D. L. \& Whitcomb, R. F. (1995). Spiroplasma ixodetis sp. nov., a new species from Ixodes pacificus ticks collected in Oregon. Int J Syst Bacteriol 45, 23-28.

van den Ent, F., Amos, L. A. \& Löwe, J. (2001). Prokaryotic origin of the actin cytoskeleton. Nature 413, 39-44.

Walsh, P. S., Metzger, D. A. \& Higuchi, R. (1991). Chelex 100 as a medium for simple extraction of DNA for PCR-based typing from forensic material. BioTechniques 10, 506-513.

Wedincamp, J., Jr, French, F. E., Whitcomb, R. F. \& Henegar, R. B. (1996). Spiroplasmas and entomoplasmas (Procaryotae: Mollicutes) associated with tabanids (Diptera: Tabanidae) and fireflies (Coleoptera: Lampyridae). J Invertebr Pathol 68, 183-186.

Weisburg, W. G., Tully, J. G., Rose, D. L. \& 9 other authors (1989). A phylogenetic analysis of the mycoplasmas: basis for their classification. J Bacteriol 171, 6455-6467.

Whitcomb, R. F. (1983). Culture media for spiroplasmas. Methods Mycoplasmol 1, 147-158.

Whitcomb, R. F. \& Coan, M. E. (1980). Comparative growth of flower, bee and citrus spiroplasmas. In Proceedings of the 90th General Meeting of the American Society for Microbiology, p. 79. Washington, DC: American Society for Microbiology.

Whitcomb, R. F. \& Hackett, K. J. (1996). Identification of mollicutes from insects. In Molecular and Diagnostic Procedures in Mycoplasmology, vol. 2, pp. 313-322. Edited by J. G. Tully \& S. Razin. New York: Academic Press.

Whitcomb, R. F., Tully, J. G., McCawley, P. \& Rose, D. L. (1982). Application of the growth inhibition test to Spiroplasma taxonomy. Int J Syst Bacteriol 32, 387-394.

Whitcomb, R. F., Chen, T. A., Williamson, D. L. \& 7 other authors (1986). Spiroplasma kunkelii sp. nov.: characterization of the etiological agent of corn stunt disease. Int J Syst Bacteriol 36, 170-178.

Whitcomb, R. F., Bové, J. M., Chen, T. A., Tully, J. G. \& Williamson, D. L. (1987). Proposed criteria for an interim serogroup classification for members of the genus Spiroplasma (class Mollicutes). Int J Syst Bacteriol 37, 82-84.

Whitcomb, R. F., Hackett, K. J., Tully, J. G., Clark, E. A., French, F. E., Henegar, R. B., Rose, D. L. \& Wagner, A. C. (1990). Tabanid spiroplasmas as a model for mollicute biogeography. Zentbl Bakteriol Suppl 20, 931-933.

Williamson, D. L. \& Poulson, D. F. (1979). Sex-ratio organisms (Spiroplasmas) of Drosophila. In The Mycoplasmas, vol. 3, pp. 175-208. Edited by R. F. Whitcomb \& J. G. Tully. New York: Academic Press.

Williamson, D. L., Whitcomb, R. F. \& Tully, J. G. (1978). The spiroplasma deformation test, a new serological method. Curr Microbiol 1, 203-207.

Williamson, D. L., Tully, J. G. \& Whitcomb, R. F. (1979a). Serological relationships of spiroplasmas as shown by combined deformation and metabolism inhibition tests. Int J Syst Bacteriol 29, 345-351.

Williamson, D. L., Blaustein, D. J., Levine, R. J. C. \& Elfvin, M. J. (1979b). Anti-actin-peroxidase staining of the helical wall-free prokaryote Spiroplasma citri. Curr Microbiol 2, 143-145.

Williamson, D. L., Tully, J. G. \& Whitcomb, R. F. (1989). The genus Spiroplasma. In The Mycoplasmas, vol. 5, pp. 71-111. Edited by R. F. Whitcomb \& J. G. Tully. San Diego, CA: Academic Press.

Williamson, D. L., Whitcomb, R. F., Tully, J. G. \& 10 other authors (1998). Revised group classification of the genus Spiroplasma. Int J Syst Bacteriol 48, 1-12.

Woese, C. R. (1987). Bacterial evolution. Microbiol Rev 51, 221-271. 
Woese, C. R., Maniloff, J. \& Zablen, L. B. (1980). Phylogenetic analysis of the mycoplasmas. Proc Natl Acad Sci U $S$ A 77, 494-498.

Woese, C. R., Stackebrandt, E. \& Ludwig, W. (1985). What are mycoplasmas: the relationship of tempo and mode in bacterial evolution. J Mol Evol 21, 305-316.
Ye, F., Laigret, F., Carle, P. \& Bové, J. M. (1995). Chromosomal heterogeneity among various strains of Spiroplasma citri. Int J Syst Bacteriol 45, 729-734.

Ye, F., Melcher, U., Rascoe, J. E. \& Fletcher, J. (1996). Extensive chromosome aberrations in Spiroplasma citri strain BR3. Biochem Genet 34, 269-286. 